\title{
Is Korybantic Performance a (Lyric) Genre?
}

\author{
Mark Griffith*
}

\section{Introduction}

Korybantic rites and other celebrations of similar type, involving loud and exciting music and strong emotional affect, were widely practiced throughout the Greek world, but they are not normally discussed as examples of "Greek lyric," either by ancient or by modern critics. In this chapter, I want to explore not just the reasons for this omission but also some key characteristics of Korybantic performance ${ }^{1}$ that serve to illustrate the extent to which the study and interpretation of Greek "song culture," by focusing - for obvious reasonsso intensively on the verbal aspects of that culture's high-end achievements (i.e., the surviving poetry of Sappho, Pindar, Anacreon, et al.), has tended to underestimate the abundance and significance of some of the popular song and dance forms that do not survive as written texts. Elite biases, ancient and modern, have thus, I suggest, rather distorted our picture of the archaic and classical music scene overall, and have unduly marginalized certain types of lyric performance that deserve to be included more squarely within our critical assessments and definitions. My discussion will also, I hope, contribute another relevant dimension to this volume's range of approaches to the question of what constitutes a "lyric genre," and what poetic, social, and performative criteria should be invoked in answering such a question.

\section{Some Working Definitions of "Genre," "Lyric," and "Song”}

Defining what we might mean by a "genre" of "lyric poetry" in the context of ancient Greek song culture is open to many different approaches and biases. This whole volume is testimony to that range of difference. Whether we prefer

* I am very grateful to the three Editors, especially Naomi Weiss, for constructive criticism and advice at various stages of the writing and revising of this chapter.

1 As will become clear during the course of this chapter, I will be lumping together under the term "Korybantic" a fairly wide range of related performance-types, almost all of them involving vocalizing and dancing accompanied by double-pipes (auloi) and/or percussion instruments as components of an exciting and mood-altering ceremony. 
to emphasize occasion, content, purpose and social function, formal structure, rhetorical strategies, verbal registers and metrical distinctions, persona of the author/singer, or any other set of conventions and poetic/performative "rules," may be largely a matter of taste and critical allegiance. ${ }^{2}$ By any definition, however, specific conventions and distinguishing marks, or actual rules, were always involved in the performance of any particular type of "song" created, performed, and reperformed in archaic and classical Greece, even whilenotoriously—there will always remain a number of poems and song-types that resist easy classification into any one generic category.

"Song" involves a combination of words and music. Greek "song-culture" can and should therefore be discussed in terms both of its verbal content and of its melodic, rhythmic, and textural elements. ${ }^{3}$ Unfortunately, however, almost all of the musical components of our surviving lyric poems are lost to us, except for their metrical structures and a few verbal self-references. ${ }^{4}$ Consequently we are in the habit of discussing them almost exclusively in terms of their verbal elements, i.e., treating them simply as "poems" and works of literature, even though it will often have been the musical (and visual) elements that made the strongest impact on the ears, eyes, and minds of their original audiences. ${ }^{5}$

Sidestepping questions (explored by several other chapters in this volume) about the validity or stability of "generic" categories of lyric poetry within the song-culture of the archaic and classical periods, as defined by themselves or by Hellenistic and later critics, I want in this chapter to focus instead on some of the musical differences that might sometimes serve to categorize particular

2 My own critical debts and allegiances with regard to genre theory are mostly to the following: Färber 1932; Frye 1957; Olson 1969, 1976 (i.e., the school of "Chicago Critics," who, following Aristotle, treated lyric poetry for the most part as a branch of rhetoric); likewise Cairns 2007 (first ed. 1972); also Rotstein 2010, 2012. For further discussion see too Herington 1985; Conte 1992; Nagy 1994-1995, 2016; Calame 1998a; Ford (this volume).

3 In the Greek context, one might say also that song usually involved bodily movement, often in the form(s) of "dance," as well as some kind of audience response. These corporeal aspects of song-performance will accordingly be considered (intermittently) in what follows.

4 See Prauscello 2012 for Pindaric self-references to "Dorian," "Aeolian," "Lydian," and other melodies. Within the lyrics of Greek tragedy, such self-reference is not uncommon: see esp. Weiss 2018. No actual melodies survive for any non-dramatic Greek songs composed earlier than the Hellenistic period. For full discussion of ancient Greek melodies and instruments, see Barker 1984, 1989 passim; West 1992; Matthieson 1999; Pöhlmann and West 20o1; Hagel 2010.

5 So e.g. Hes. Theog. 1-115; cf. Naerebout 1997; Peponi 2012; Butler and Purves 2013; also Martinelli 20ogb; Schironi (this volume) for discussion of ancient scholarly comments about the musical and choreographic elements of archaic lyric, showing that their comments, limited as they are, are almost entirely derived from the words of the written texts themselves. 
types of vocal performance within this or that clearly identifiable type, and on audience affect (the aesthetic/emotional impact on the listeners) as a measure of these differences.

However we choose to define "genre," we can generally expect to understand any particular song better and enjoy it more if we recognize what kind of poem/utterance/performance it is, and this usually entails being somewhat familiar with the musical as well as verbal idiom(s) within which it is composed. In the ancient Greek world, musical categories (i.e., differentiation in terms of tonos, harmonia, rhythm; formal compositional structures; solo voice vs. chorus; also choice of accompanying instruments) were normally established by quite objective criteria and were somewhat consistently recognized. ${ }^{6}$ In particular, musical genres were publicly registered and announced

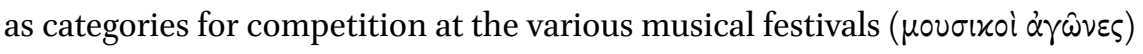
observed all over the Greek world. ${ }^{7}$

Ancient discussions of poetry and literary form, and ancient categories for musical competition, did not apparently recognize "Korybantic," or other kinds of Bacchic/ecstatic performance, as a "genre." But in discussions of music and its effects this kind of subliterary performance sometimes loomed quite large. My chapter is intended as an ethnomusicological inquiry into this discrepancy, focusing on this one particular genre, or type, of Greek musico-religious performance, with a view to clarifying some questions about the nature, purpose(s), and critical reception of a widespread and culturally important phenomenon that has tended to fly somewhat under the radar of modern scholars writing about ancient Greek song culture. I will suggest that whereas Korybantic and other such performance was regarded by most elite writers in antiquity (if it was mentioned at all) as merely a kind of crude psychotherapy and/or vulgar religious extravaganza, of negligible social or artistic worth, the evidence (especially that provided by Plato and by Aristotle in the Politics) suggests that it was in fact widely experienced and enjoyed by all levels of society, and might properly be classified (by us moderns) as a distinct and socially important lyric genre.

Ancient Greek "song culture" has been much discussed and analyzed, since at least the 1970s, in reaction against a previous—and long-standing —overemphasis on the "literary" qualities of the surviving texts. As is by now widely recognized, the texts that we refer to generally as "archaic/classical Greek lyric poetry" were not composed originally nor primarily to be read on the page,

6 See esp. Arist. Pol. bk. 8; [Arist.] Pr. chs. 11, 19, De Audib., P. Hibeh 1.13; further West 1992; Rotstein 2012.

7 Kotsidu 1991; Manieri 2009; Power 2010; Rotstein 2012; etc. 
but to be performed — sung, and often danced as well, i.e., to be heard and seen. ${ }^{8}$ The range of different types of musical performance, even of vocal performance, was broad, and the processes whereby some (relatively few) of these songs ever came to be written down and preserved were many and various. Most musical-poetic performances surely never existed as reading-texts, and the literary texts that we happen to possess will have tended to be, on the whole, the cream of the crop, selected by contemporaries and by later critics/scholars/educators precisely because of their superior verbal quality and prestige. ${ }^{9}$ But in the case of many, perhaps most, of the public and private performances that comprised "Greek song culture," the chief point and impact of the performances, I would suggest, resided less in the details of the words that were sung - the verbal text-than in other aspects, such as the melody, rhythms, choreography, instrumental and vocal timbres, the physical attributes (including costumes as well as gestures) of the performers, and the collective energy of the whole group.

As we all know, a song with only minimal words-and these quite predictable, repetitive, and often banal, perhaps improvised and variable - can still be a powerful and engaging form of cultural expression, celebration, and communication. Some popular songs are poetic (verbal) masterpieces; but in many other cases, it is the quality of the voice(s) and instrumental accompaniment, the affective interplay between sounds (music) and sights (bodily movement, whether as formal "dance" or in other kinds of corporeal expression) that make a "song" into a classic, a hit, a cultural statement. ${ }^{10}$ In a record store, the 45 s or LPs or CDs containing these various different kinds of songs have always been placed in separate "bins"- they belong to different genres; and Grammies are likewise awarded to singers and groups according to various categories that usually have more to do with musical idiom and style than the actual verbal content. ${ }^{11}$

Poems that were inscribed on stone or bronze-i.e., for reading-were generally composed in non-lyric meters, usually hexameters or elegiac couplets.

9 See esp. Pfeiffer 1968; Reynolds and Wilson 1991; Rutherford 2001: 137-158; Acosta-Hughes 2010 for the ancient reception and textual transmission of the Greek "lyric" corpus.

10 If we look back, e.g., to the era of the 1960s and 1970s, Bob Dylan and Leonard Cohen can be seen occupying one end of this spectrum-these are "wordsmiths, poets" whose actual singing voices are quite limited. On the other end, e.g. the Isley Brothers' "Twist and Shout" (subsequently taken over by the Beatles), or James Brown's "Cold Sweat" spoke to their audiences largely by other means than words. In all four of these cases, their songs quickly became and have remained classics.

11 See, e.g., the scores of separate categories listed in the article "Popular Music Genre" on Wikipedia, accessed June 23, 2016: https://en.wikipedia.org/wiki/List_of_popular_music genres. 
For ancient musical festivals and contests we are fairly well informed as to the different categories of performance, both instrumental and vocal: prizes were normally awarded for kitharoidia, kitharistike, auloidia, auletike, and rhapsoidia, sometimes for dithyrambos, for tragoidia and/or satyr-play and/or komoidia, and even for sophistike. ${ }^{2}$ Virtually none of the texts (words) for any of those thousands of aulodic or kitharodic songs (and very few indeed even of the large-scale choral dithyrambs) have survived; but it is clear that the solo musical events were very popular in their day, and the names of many of the victorious singers and instrumentalists are recorded on stone and, in the case of the most distinguished, in anecdotes and "histories" of Greek musical culture (as we learn from such late sources as Athenaeus and pseudo-Plutarch's On Music). ${ }^{13}$

We are entitled, then, to regard kitharody or aulody not only as musical genres but perhaps as lyric genres as well (since they involved songs). The generic conventions for kitharodic performance were apparently somewhat standardized: a kitharoidikos nomos was a suite of movements, often similar to the musical structure of a purely instrumental competition piece for kithara or auloi. ${ }^{14}$ The surviving fragments of Timotheus and other fifth- and fourth-century performers give us further clues about the language, typical themes, and idioms of such poems. ${ }^{15}$ But these authors too represent the literary high-flyers, and we get a strong impression from descriptions of musical performances of that era that for the most part the audience and judges were more interested in the quality of voice, melody, and delivery, and in instrumental virtuosity, than in subtleties of linguistic structure, imagery, and argument. ${ }^{16}$

12 Kotsidu 1991; Csapo and Slater 1995; Wilson 2000; Le Guen 2001; Manieri 2009; Power 2010; Rotstein 2012; Kowalzig and Wilson 2013; LeVen 2014. Most of our direct epigraphic evidence about festival competitions comes from the third century вСЕ or later, but the basic categories were mostly in place already by the sixth century. For choral contests, see Wilson 2000 (tragedy, comedy and dithyramb); Kowalzig and Wilson 2013 (dithyramb); for Paean, see Rutherford 2001; also in general Kowalzig 2007b.

13 For kitharoidia in particular, see Power 2010. In general, for a prosopography of Dionysian Artists, see Stefanis 1988; Le Guen 2001. For Athenaeus, pseudo-Plutarch et al. on ancient Greek musicians, see esp. Barker 1984: 205-303; West 1992; Olson 2012; and the papers in Gentili 2012.

14 Power 2010: $185^{-234}$.

15 See Campbell 1993 vol. 5; LeVen 2014.

16 Even in the Theater of Dionysus at Athens, the musical (i.e. auditory and choreographic) effects often dominated the audience's experience, from the time of Phrynichus, Pratinas, and Aeschylus through into later centuries. Cf. e.g., Pratinas $(\operatorname{Tr} G F$ 1) 4 fr. 3 , "Aeschylus"

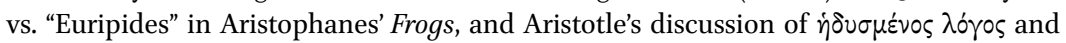
$\mu \varepsilon \lambda \circ \pi \circ i^{\alpha} \alpha$ (Poet. 6.1449b25-34), with e.g. Sifakis 2001. 
These examples should suffice to remind us that ancient Greek "song culture" operated along a spectrum, just as, for example, contemporary rock, pop, folk, soul, hip-hop, and techno music does, with some kinds of songs (song-genres) relying more on their words, others more on their rhythms, melodies, harmonies or vocal-instrumental timbres (and/or the performers' physical appearance), while several occupy a middle ground in which words and music are evenly balanced. In this chapter I will be focusing on some of the Greek song-types that existed on the less verbal and more rhythmic-textural (and corporeal) end of that spectrum, in particular "Korybantic" and other "enthusiastic/orgiastic" performances, and exploring the question whether or not such performances should be regarded as constituting a recognizable and distinctive "lyric genre" - and, if so, what further implications this might have for our overall understanding of the different possible statuses and functions of "lyric genres" within Greek song culture at large.

One way of thinking about the spectrum of song-types that I have outlined here, and the place of korybantic-type performance within it, is in terms of a "grid" of performance practices, on which we can plot the various different forms, instruments, and concepts of ancient Greek musical culture. In Table 8.1, I have organized and presented such a grid so as to illustrate at a glance how the forms of music-making that were most socially respectable, morally approved, and aesthetically admired (at least among our elite literary sources) tend to coalesce around particular instruments, particular divinities, particular types of melody, and a restricted and distinct range of uses of the human voice, while other instruments, divinities, tunings, and modes of vocalizing are associated more or less definitely with non-elite, and in several cases non-Greek, musical performance. ${ }^{17}$

The instruments, vocal sounds, and tunings/styles that are located towards the left-hand side of the grid are generally described by our elite sources as being more appropriate to "high" musical art and to male citizen performance and listening, while those on the right-hand side are generally regarded as more feminine and/or exotic and foreign, more déclassé or morally suspect, and hence to be either ignored completely in the educationalists' and moralists' accounts or to be classified as unsuitable for male citizen performance. In parallel with these tendencies, and providing a vital form of cultural justification for them, we may align the religious elements, with Apollo (and his

17 This grid, or spectrum (which obviously owes much to Bourdieu 1987 and 1990), is largely synchronic and is intended more as a heuristic than as a rigorously analytic device. 


\section{Male}

Greek (esp. “Dorian”) strong, free, direct, dominant regular/regulated, measured rational, civilized normal—tight, tense, straight simple, plain orthos, ithus, gumnos, haplous

\section{IMAGINED CHARACTERISTICS}

\section{Female}

foreign/barbaros/Asian (or "Ionian")

weak, delicate, slavish

irregular, wild/uncontrolled, promiscuous emotional, irrational ("natural"?)

bent, slack, deviant, "queer" adorned, intricate, cosmetically enhanced poikilos, polychordos

\section{INSTRUMENTS USED: STRINGS vS. PIPES and PERCUSSION}

lyres (lura, kithara) ${ }^{\text {a }}$

pipes (auloi)

percussion (tumpanon, seistron, etc.)

TYPES of TUNINGS/SCALES (harmoniai, tonoi)
Dorian
Phrygian
Ionian/Iasti
Lydian, etc.

\section{MUSICAL DIVINITIES}

Apollo, Hermes

Dionysus, Aphrodite

(Zeus, Athena ...)

Rhea, Cybele, Sabazius, Bendis, et al.

Kouretes, Korybantes

\section{USES of VOICE and LANGUAGE}

$\begin{array}{ll}\text { logos (words, language, ratio) aude (human voice) } & \begin{array}{l}\text { phōne (animal/human/ } \\ \text { instrumental "voice") }\end{array}\end{array}$

\section{DANCE and/or OTHER CORPOREAL ACTIVITY}

symmetrical, disciplined, restricted, restrained unpredictable, free-form,

unrestricted, abandoned

\section{TYPICAL SONG-TYPE/LYRIC GENRE}

$\begin{array}{lll}\text { paean } & \text { threnos } & \text { dithyramb }\end{array}$

a Several (important) differences can be mapped within the broad range of stringed instruments: but these differences are not significant for the purposes of my chapter. See further Maas and Snyder 1989; West 1992: 49-6o, 70-8o; Bundrick 2005: 13-34, 103-131; Griffith 2017. 
parents $)^{18}$ at the left end, and more exotic divinities such as Cybele, Sabazius, Dionysus, and the Korybants at the right: ${ }^{19}$ for different religious ceremonies and rituals might employ distinctly different instruments and different kinds of human vocalizing.

So, for example, a paean to Apollo, composed in Dorian mode, sung in regular strophic stanzas by a stationary soloist or by a chorus dancing in formation to the accompaniment of kithara or lyre, would be located securely at the left end of the grid, while an aulos- and percussion-fueled song in astrophic metrical units (perhaps even improvised) addressed to Cybele or Dionysus, with frequent non- or semi-verbal vocalizings and ululations, would sit at the opposite (right) end. Not quite so far to the right we might locate e.g. a "Carian lament" 20 or a Euripidean monody in the theater-though the fact that the latter is performed by a male actor who is only artfully pretending to be a lamenting woman or foreigner might modify an audience's assessment.

Several of the key oppositions in this schema correspond closely to oppositions outlined in Book 3 of Plato's Republic, where Socrates explains why in the ideal city of Kallipolis the young future guardians and philosopher-kings should not play or listen to any instrument except for the seven-string lyre or kithara, should not sing or hear songs in which the melodic or rhythmic elements dominate over the verbal ones, and should only be exposed to Dorian or Phrygian tunings (no Lydian, Ionian, etc.). ${ }^{21}$ Multi-stringed instruments are explicitly banned, as are the pipes (auloi); ${ }^{22}$ and percussion instruments are

18 In the Homeric Hymn to Apollo, Zeus and Leto do not join the other (young) Olympian divinities in dancing, singing, and "sporting" ( $\pi \alpha i \zeta 0 v \sigma \iota)$ together when their son performs on the kithara (182-206): Apollo's parents prefer to sit, listen, and watch, rejoicing in the whole auditory/visual/social experience (204-206). Aristotle likewise observes (Pol. 8.5.1339b6-10) that Zeus himself does not ever play an instrument (similarly, Aristotle's

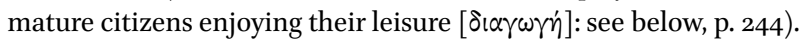

19 The Greeks regarded several of their divinities as being highly musical, but not all in the same ways. As Nietzsche and many others have noted, Apollinian music tended to be different in flavor, instrumentation, and effects from Dionysian music, and as we shall see, "Korybantic" performance belongs quite far to the right side of our spectrum, overlapping with the music of Dionysus and Cybele. On the complex issue of the gendering of Greek music in general, see Griffith 2017 and forthcoming.

20 Pl. Leg. 7.80oe, Ar. Ran. 1296, etc.; cf. Prauscello 2014: 183-191.

21 Pl. Rep. 3.397-402a; see further e.g. Anderson 1966; Barker 1984: 124-136; Wallace 2005; Pelosi 2010: 36-48. On the unexpected favor shown here to Phrygian (as well as to the anticipated Dorian) mode, see e.g. Gostoli 1995 .

22 All of these banned instruments were apparently common in the music-making of Assyria, Phrygia, and elsewhere in the Near East during the ninth to seventh centuries BCE, i.e., the prime sources of early Greek music (Franklin 2002). In Athenian vase paintings of the classical period, multi-stringed instruments are always played by women (Bundrick 
not even mentioned. ${ }^{23}$ The musical regulations for the citizens of Magnesia in Plato's Laws seem to follow similar restrictions, ${ }^{24}$ though there the main focus is on dance and choral performance and less attention is paid to the citizens' actual playing of musical instruments.

The guidelines proposed by Aristotle in the Politics for the musical education of young (male) citizens in school are likewise strictly in favor of lyre and kithara over pipes, and of Dorian melodies over any other. ${ }^{25}$ But Aristotle, as we shall see, has a much broader interest in the overall music scene of a typicalor ideal—community, and of the different possible — and desirable-functions for various kinds of music than we find anywhere in Plato. Aristotle consequently will serve as one of our chief guides in locating and interpreting the nature of "sacred, orgiastic" (including "Korybantic") music and of the psychosocial function(s) of such performances in classical Greece.

In the rest of this chapter, therefore, I will first sketch the place occupied by Korybantic and other "enthusiastic" kinds of music within Aristotle's culturalpolitical universe. Then, after surveying briefly the nature of "trance" musical performances as a world-wide phenomenon, I will discuss the particular forms that such performances (including Korybantic ceremonies) seem to have taken in the ancient Greek world, noting the common elements of intense audience affect, widespread corporeal and kinetic engagement, and predominance of female and non-elite participation, all of which doubtless contributed to the relatively déclassé and/or neglected status of such musical activity among the writings of most ancient critics. I will conclude with some remarks about the place of these performances - and other performances that belong on the farright-hand side of our "grid" - within our broader understanding of ancient concepts of genre.

2005: 30-33). For discussion of the growing disapproval of the auloi among elite Athenian intellectuals from the mid-5th century onwards, see Wilson 1999; Martin 2003; Bundrick 2005 .

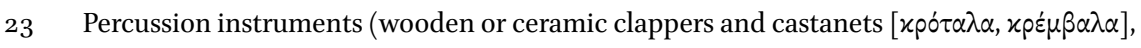

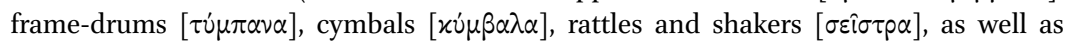
wooden or bronze bull-roarers [ $\hat{\rho} o ́ \mu \beta o l])$ were all quite extensively used in Greek and other Near Eastern musics: West 1992: 122-128; Mathiesen 1999: 162-177; Bundrick 2005: 46-48; Kolotourou 2011. But for the most part Greek educationalists and music theorists disregard them, and when these instruments are mentioned in high literature they are usually treated as belonging to women or foreigners (or both). See further below, p. 258 .

24 Pl. Leg. 653c-66oc, 664b-671a, 70oa-701b, 798d-8o2e, 812b-e; see Barker 1984: 140-168; Peponi 2013b; Prauscello 2014.

25 Arist. Pol. 1341a1o-41b8; 1342a29-42b17; see Newman 1902; Dreizehnter 1970; Lord 1982; Kraut 1997 ad loc.; also Barker 1984: 172-182. 


\section{Aristotle and the Genre of "Enthusiastic" (including Korybantic) Music}

Aristotle is generally our most helpful source of information and ideas about social aspects of ancient Greek musical performance and listening. ${ }^{26}$ In Book 8 of the Politics, Aristotle seeks to describe and explain the different psychological and cultural functions that various kinds of music can serve, and in the course of his discussion he provides interesting perspectives on the effects and value of Korybantic and other kinds of what he terms "enthusiastic" and "sacred" music-making. Aristotle is also valuable to us, of course, as the first author whose work survives to have undertaken a somewhat systematic analysis of artistic and poetic "genres," i.e., the Poetics. Unlike Plato, Aristotle can generally be trusted to report fairly straightforwardly what he takes to be the commonly held opinions of his contemporaries ( $\left.\varepsilon^{2} v \delta \circ \xi \alpha\right)$ and to take these seriously as deserving discussion. His own tastes and opinions also seem to be in many respects normal and typically Greek (in contrast, again, to Plato's): sexist, racist, elitist though Aristotle may be, he nonetheless belongs among the Greek mainstream in most of his basic assumptions about the nature and purpose of human existence. In particular, he recognizes the positive value of pleasure, bodily as well as spiritual/mental, and of material processes and goods as well as intellectual ones; and he is especially interested in the pleasures provided by music.

Aristotle emphasizes the importance and pervasiveness of music in human communities, and devotes considerable attention to the question of how it ought to be deployed in his model polis: indeed the Politics ends with his discussion of music. ${ }^{27} \mathrm{He}$ recognizes that music in general is enjoyable (for everyone, of all ages and character-types: $1340 \mathrm{Oa}-5 ; 1342 \mathrm{~b} 17-32$ ) in acoustic/sensory terms (i.e., the sounds of music are pleasant to our ears), and that it contributes to the well-being of the various (disparate) members of any given society-even while he also argues, like Plato, that certain kinds of music, listened to in the correct manner, may provide a superior benefit to those who are discriminating enough to appreciate them. In his (rather rambling, and in places disjointed)

26 In addition to his remarks in Politics Book 8 about the educational and political functions of music (discussed in what follows), Aristotle is also valuable to us as a theorist of acoustics, aesthetics, and psychology. See esp. Ar. Poet., De an. 2.8; also ps.-Arist. De audib. and $\operatorname{Pr}$. (mainly chs. 11 and 19), both clearly Peripatetic but not authentically Aristotelian.

27 This discussion occurs in the course of Aristotle's larger discussion of citizen education, which has led some commentators-mistakenly—-to try to limit Aristotle's comments to their potential educational implications. 
analysis, Aristotle ends up laying out a basic framework in which musics of various kinds, performed by different practitioners and for different audiences, are to be classified in five basic categories, each of which serves a somewhat different social function - though it seems that in some cases the same musical performance might fall into more than one category, depending on its audience. $^{28}$

Aristotle's categories of musical types, or functions, are not as neatly laid out for us as we might wish. In fact, he deploys two different systems for categorizing music: one in terms of types of melodies ( $\mu \dot{\varepsilon} \lambda \eta$, $\dot{\alpha} p \mu o v i \alpha l)$, according to the way that "some philosophers distinguish/define things" (1341b32-34: $\dot{\omega} s$

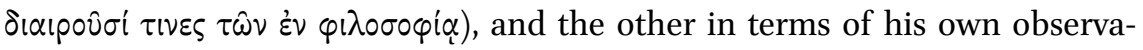
tion of music's psycho-social effects. According to the first system, there are three basic types (we might say, "genres") of melody: "ethical," "practical," and "enthusiastic."29 According to the second system, which forms the organizing principle for most of Aristotle's discussion in Politics Book 8, there are four main functions for music in society: (1) relaxation, release of stress, fun ( $\dot{\alpha} \dot{\alpha} \pi \alpha \nu-$ $\sigma ı \zeta, \ddot{\alpha} v \varepsilon \sigma \iota \varsigma, \pi \alpha ı \delta$ ' $)$; (2) ethical improvement, especially for the young ( $\pi \alpha ı \delta \varepsilon i \alpha)$; (3) development and refinement of good taste in leisured/aesthetic critique and appreciation ( $\delta(\alpha \gamma \omega \gamma)$ ); and (4) arousal of strong emotion and affective

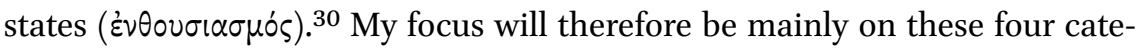
gories that Aristotle discusses in detail—especially the category of "enthusiastic" music.

28 This whole lengthy passage (1339a11-1342b32) presents several minor detours and also a number of textual difficulties and uncertainties, even while the main threads of Aristotle's argument remain fairly clear and self-consistent. Scholars disagree as to how relevant

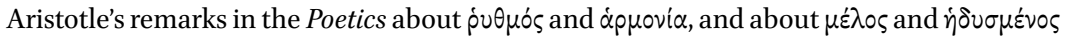
$\lambda$ 'ós, or his and his students' discussions of the effects of sound on the body and soul in any of his more technical works (De an. esp. 2.8, De audib., Pr., esp. chs 11 and 19), are for the interpretation of the Politics. My own opinion is that there is no good reason not to read these works and these passages in light of one another. In general, for commentary and interpretation of the musical content of Politics 8, see esp. Newman 1902; Lord 1982; Barker 1984: 170-182; Kraut 1997; Sifakis 2001; Halliwell 2011: 236-249.

29 Of these three categories, "ethical" and "enthusiastic" are discussed in detail by Aristotle,

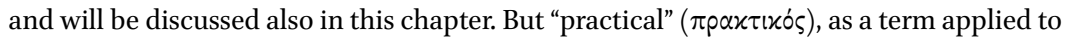
harmoniai, is never explained by Aristotle in the Politics (see n. 30). It presumably refers to non-"enthusiastic" (i.e., non-Phrygian) music that is played in contexts of everyday life and work (rather than for relaxation and entertainment), e.g., in factories, for healing, on ships (to help rowers keep time), for gymnastic and athletic training sessions, etc. Barker

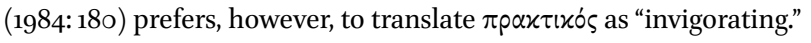

30 In two-or possibly three-places (1341b34; 42a4; 42a15?), Aristotle does use the term "practical" as a possible fifth category, but without any explanation: see n. 29; also n. 39

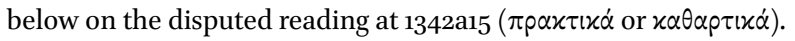


But before we examine in more detail these four categories, we need to pause to clarify an important question concerning the short-term vs. long-term "ethical" impact of music on the soul, according to Aristotle. As he launches himself into his discussion of the role of music in the education of young future citizens, he characteristically pauses to raise some fundamental questions:

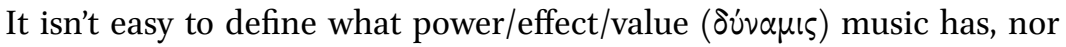

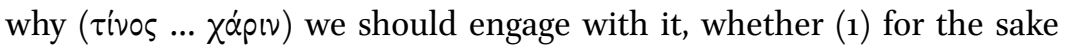

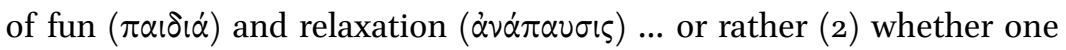

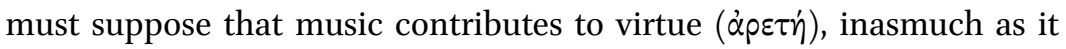

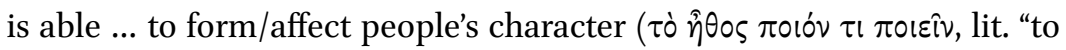
render [someone's] character of such-and-such a kind") by accustoming

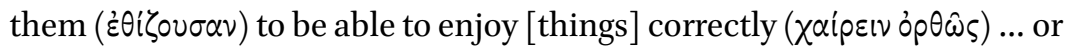
whether (3) it contributes to leisure activity ( $\delta(\alpha \gamma \omega \gamma \eta)$ and to intelligent

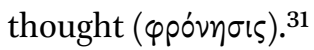

ARIST. Pol. 1339a14-26

A little later (1340a14-28) Aristotle observes as a basic fact that "music is something enjoyable" ( $\tau \hat{\omega} \nu \dot{\eta} \delta \varepsilon \dot{\varepsilon} \omega \nu$, lit. "[one] of the pleasant [things]"), while also suggesting that acoustic/musical stimuli make an unusually strong affective impact on the soul; and he goes on to claim (following the strong critical currents of his day stemming from Damon of Oea and Plato) that the moods or emotions present in and conveyed by melodies and rhythms are "similar to" ( $\left.\delta \mu o เ \omega^{\prime} \mu \alpha \tau \alpha\right)$ or "expressive/imitative of" ( $\left.\mu \mu \eta \dot{\eta} \mu \alpha \tau \alpha\right)$ actual moods and emotions that are produced by events in the real world. ${ }^{32}$ Then he adds: "For we change [in] our soul when we listen to such [affective rhythms and melodies]" ( $\mu \varepsilon \tau \alpha-$

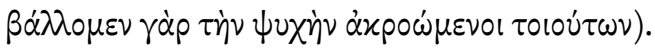

31 It is noticeable that here Aristotle omits "enthusiastic" music from his list and proposes only three functions, one of several indications that his discussion in Book 8 of the Politics exists in a somewhat preliminary, unrevised, and even muddled state. But as I will attempt to demonstrate in what follows, not only does he credit "the philosophers" with including enthusiastic music as one of the three basic types (above, n. 29) but he also himself devotes considerable attention to this a little later on (below, pp. 245-248).

Aristotle suggests that when music is/sounds "angry" or "mild," "courageous" or "restrained," these affective qualities in the music constitute "likenesses of the actual natures"

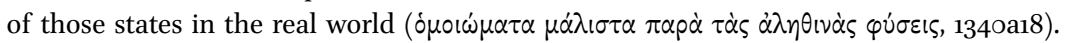
This question, how and in what sense music can be or can sound (i.e., strike listeners as being) "emotional," and how music is able to trigger the strong affective states that it demonstrably does, continues to be hotly debated by musicologists, neuroscientists, and philosophers: see e.g. Meyer 1956; Kivy 1989, 199o; Patel 2008; Juslin and Sloboda 20o1; Bicknell 2009. 
Does Aristotle think that every moment spent listening to an affecting, emotionally arousing piece of music (or watching an affecting tragedy, for that matter), produces a lasting effect (a "change") in the "character" of a person's soul? (This appears to be e.g. Plato's view, and is one of Socrates' chief reasons for banning most tragic performances from Kallipolis.) Or does Aristotle make a distinction between habitual listening to certain types of character-building music (especially for the young), on the one hand, and occasional listening to various kinds of more or less affecting music (or watching pity- and fearinducing tragedies in the theater) by adults, on the other? I believe that the latter is Aristotle's position (though he may indeed vacillate a bit, during the course of his discussion in Politics 8). For Aristotle, listening to emotionally arousing music of a "non-ethical" kind can be both enjoyable and worthwhile for all kinds of people, and this is because the affective state that is produced by the music is short-term and transitory. (The same is true for the enjoyment of tragedy.) Aristotle thus recognizes that one major "genre" of music - which must necessarily include songs as well as purely instrumental performancesis designed and experienced primarily for its affective qualities, rather than for its verbal (intellectual) content or ethical impact. We shall return to this issue at the end of this chapter. But first we need to survey in a little more detail Aristotle's account of the four (or five) basic functions for music in society.

The first and most obvious function of music that he outlines is also the most pervasive: (1) Relaxation, release of stress, fun ( $\alpha \dot{\alpha} \alpha \dot{\alpha} \alpha \nu \sigma \iota \varsigma, \alpha^{\prime} \nu \varepsilon \sigma \iota \varsigma, \pi \alpha \iota \delta 1 \alpha$ ). Music is greatly enjoyed by absolutely everyone (1339b2o), young or old, male or female, gentleman, laborer, or slave, and its ability to provide harmless pleasure (like, e.g., sleep, or drinking, or dancing, as Aristotle suggests at 1339a17-21) is recognized as a benefit by all, especially by those whose lives are full of stress

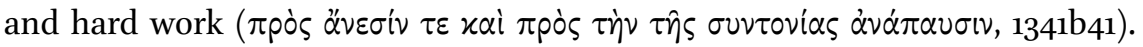
Thus music in general is recreational, relaxing and enjoyable, with no harmful side-effects—-definitely a social good. ${ }^{33}$

(2) Like Plato's Socrates and many other ancient philosophers and educational theorists, Aristotle also is committed to the notion that certain kinds of music can provide ethical improvement, especially for the young (Pol.1339a2o ff.

33 Aristotle does not go into detail in the Politics about the physiological and psychological mechanisms through which such "relaxation" is provided by music, nor why playing and/or listening to music is such "fun" ( $\pi \alpha \iota \delta$ ' $)$ for humans. But he appears to relate these effects to the natural human delight in rhythm, harmony, and mimesis (as in Poet. ch. 4), while recognizing (as in De an. 2.8) that sounds of all kinds cause "movement" (xivnoı) and "change" within the human ear and hence in the soul $\left(\psi v \times \eta^{\prime}\right)$, a process of stimulation that can be inherently — and harmlessly—pleasurable, just like other sensory experiences (taste, smell, touch, and sight). See further Sifakis 2001; Griffith 2018. 
and passim). Specifically, he recommends that musical pieces composed in the Dorian mode and performed on stringed instruments (cf. Pl. Rep. 397a-402a, discussed above) should be taught in school as a component of the characterformation of future citizens (1341a1o-42b17). ${ }^{34}$ Accordingly, he disapproves of aulos-music within an educational program (1341a17-24) because "the aulos is not an 'ethical' instrument but rather an 'orgiastic' one," i.e. it is not good for building a virtuous character but rather for arousing emotional responses. So, he explains (1341a22-24), "the proper occasions (xaıpoús) for using the aulos are those in which the performance $\left(\theta \varepsilon \omega p^{i} \alpha\right)$ is designed to produce emotional stimulation-and-release ( $\left.\alpha^{\prime} \dot{\theta} \alpha \rho \sigma v\right)$ rather than instruction ( $\left.\mu \dot{\alpha} \theta \eta \sigma v\right) . "$

(3) Rather nebulous-but important for Aristotle's elitist aesthetics-is music's function as an object of leisured, aesthetic critique and appreciation,

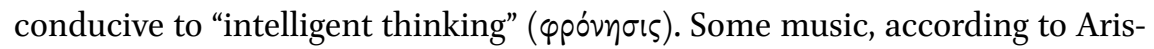
totle, should be designed and played in a refined style so as to be appreciated (though not actually performed) by highly discriminating, leisured listeners, for its own sake. This music will be performed, it appears, by professional musicians who themselves presumably lack the aesthetic discrimination of their elite audience, yet can perform the appropriate pieces with the requisite skill. Aristotle's rather evasive label for this psycho-social function, or activity, is $\delta$ ¿ $\gamma \omega \gamma \eta$ ' (lit. "pastime"), and this kind of "appreciation" of music, he insists, should be quite distinct from-and is superior to-the cruder "relaxation, fun" ( $\alpha^{\prime} v \varepsilon \sigma \iota \varsigma, \pi \alpha \iota \delta i \alpha$ ) that the lower and less refined social classes find in their music-listening. The question, whether or not Aristotle succeeds in drawing a valid distinction between these categories (1) and (3), need not concern us here. $^{35}$

34 Belief in the ethical effects of music was widespread in antiquity, but by no means universal. Thus whereas Plato takes it for granted in the Republic and the Laws that Dorian melodies will produce courageous and self-disciplined character in those who perform and listen to them, while Ionian or Lydian will produce more dissolute characters, other authors from around the same date pour scorn on the idea that musical tunings affect character and social behavior (e.g., the author of P.Hibeh 1.13, focusing on alleged differences in character between communities in different regions of Greece who are brought up on enharmonic vs diatonic tunings; see e.g. Barker 1984: 183-185).

35 In the end this distinction may be thought to amount to nothing more than a mystification of certain arbitrarily preferred kinds/modes of "relaxation" and "fun," i.e. a typical upperclass fetishizing of (high) "art" vs. (low, vulgar, cheap) "entertainment." See e.g. Bourdieu 1987; also Ford 2004. Kidd 2016 argues that Aristotle here and elsewhere always distinguishes between "play" ( $\pi \alpha \iota \delta i \alpha)$, as involving purely corporeal effects of $\alpha^{\prime} \nu \varepsilon \sigma \iota \varsigma, \dot{\alpha} \nu \alpha \dot{\pi} \pi \alpha v \sigma \varsigma$, etc., and the higher-grade psychic effects of "leisure" ( $\sigma \chi 0 \lambda \eta^{\prime}, \delta 1 \alpha \gamma \omega \gamma \eta$ ). But given Aristotle's account of sound and hearing (De an. 2.8), it is hard to see how corporeal and psychic responses can be thus kept completely separate. 
(4) Aristotle's most important category for our purposes is music's capacity to be especially affective and emotionally arousing. He frequently employs

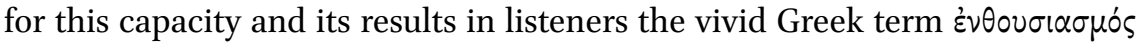
(lit. "the state of being है $20 \varepsilon \circ \varsigma^{\prime}$ " "having god inside one") along with the adjec-

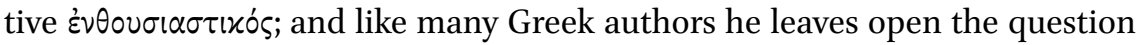
whether the term is to be understood literally or figuratively. ${ }^{36}$ Other, less colorful terms that Aristotle uses in the Politics, apparently interchangeably with

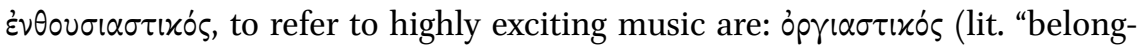

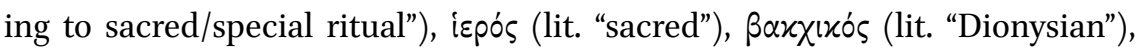
and $\pi \alpha \theta \eta \tau$ ixós (lit. "pathos-inducing," i.e. affective, emotional). ${ }^{37} \mathrm{He}$ repeatedly makes clear that this/these kind(s) of music is/are played (mostly, or always) by the pipes (auloi) and in the Phrygian mode (harmonia or tonos). ${ }^{38}$ It becomes clear as Aristotle's discussion proceeds that he thinks virtually all listeners find music of this kind to be exciting, affective, and mood-altering, even while he notes that certain especially impressionable or unstable people may be stimulated to an exceptional degree and may experience an extreme state of emotional "release" as a result ( $\varkappa \dot{\alpha} \theta \alpha \rho \sigma \iota \varsigma)$. This is the point at which Aristotle mentions what must be Korybantic or Korybantic-type performances:

It is clear, therefore, that all the musical modes (íproviaıs) should be employed [sc. in an ideal city], but not all in the same way. In education

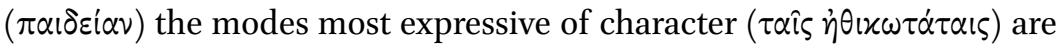
to be preferred, but in listening to the performances of others we may admit the "practical" modes ( $\pi \rho \alpha \kappa \tau i x \alpha i \varsigma)$ and the "affective" modes ( $\sigma(\alpha \sigma \tau i x \alpha i \varsigma)$ also. For any affect/emotional state $(\pi \dot{\theta} \theta 0 \varsigma)$ that exists very

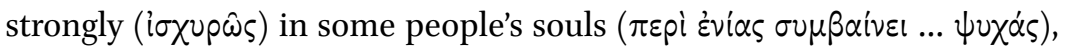

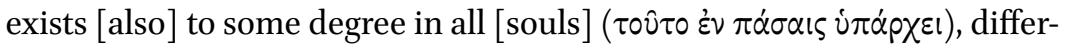
ing only in degree ( $\tau \hat{\omega} \delta \dot{\varepsilon} \hat{\eta} \tau \tau o \nu ~ . . . ~ x \alpha i े ~ \tau \hat{\omega} \mu \hat{\alpha} \lambda$ ov): for example, pity, fear,

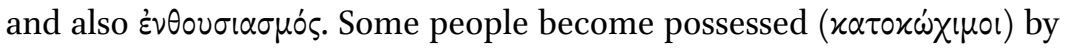

$3^{6}$ Similar ambiguity between literal and figurative reference surrounds other such terms, e.g.

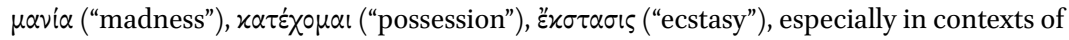
artistic creativity and religious fervor: see further Burkert 1987: 112-113; Halliwell 2011: 166179; Peponi 2012: 20-23.

37 Modern scholars have employed various translations for the kind of altered mental state

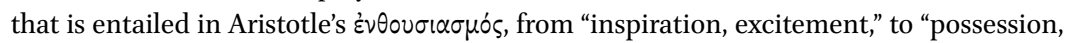
ecstasy," to outright "frenzy."

38 See esp. 1342b1-5: "Among the modes ( $\dot{\alpha} p \mu o v i \omega \hat{v})$ the Phrygian has the same impact/effect/

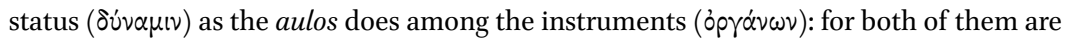
'orgiastic' and 'pathetic' ..." Thereupon Aristotle proceeds to discuss the dithyrambic performances of Philoxenus and others (1342b6 ff.). 
this movement ( $\varkappa(\eta \dot{\gamma} \sigma \varepsilon \omega \varsigma$, sc. of the soul by musical stimuli), and from

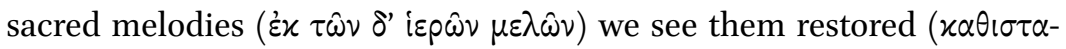
$\mu \varepsilon \dot{\varepsilon}$ ous) when they employ the melodies that especially arouse the soul

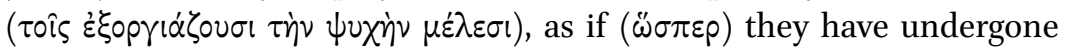
a healing process (i $\alpha \tau \rho \varepsilon i \alpha \varsigma$ ) and a "release" ( $\varkappa \alpha \theta \dot{\alpha} \rho \sigma \varepsilon \omega \varsigma)$. Those who are prone to feelings of pity and fear and those who are in general very emo-

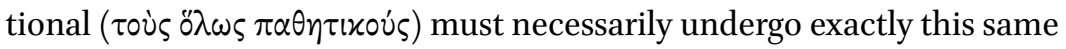
experience ( $\tau \alpha \dot{\jmath} \tau \dot{\delta} \delta \dot{\eta} \tau 0 \hat{\imath} \tau 0 \ldots \pi \dot{\alpha} \sigma \chi \varepsilon v)$ ), and everyone else too according to the degree to which each one possesses such [tendencies]; and to all of them a kind/degree of "stimulation-and-release" occurs ( $\pi \hat{\alpha} \sigma l \gamma$ r $\gamma v \varepsilon \sigma \theta \alpha i$ $\tau \imath \nu \alpha x \dot{\alpha} \theta \alpha \rho \sigma \nu)$ and they experience delight and a feeling of lightness (xov$\varphi\left(\zeta \varepsilon \sigma \theta \alpha \iota \mu \varepsilon \theta^{\prime} \dot{\eta} \delta 0 \nu \hat{\eta} \varsigma\right) .{ }^{39}$

AR. Pol. 1342a1-15

Aristotle does not mention Korybants specifically here, but it seems clear that he has in mind a spectrum of "enthusiastic/orgiastic" musical performances and experiences, ranging from all-out healing rituals in which people are "possessed ... and restored ..., as if undergoing a healing" (which sounds very Korybantic) to somewhat milder and more restrained enjoyment of e.g. "high art" auletic recitals or tragic and dithyrambic songs; and somewhere between these two extremes we might expect to situate a wide variety of other "Bacchic, sacred" musical events. Aristotle appears to consider it normal and natural that one and the same musical performance might elicit differing degrees of arousal within a group of listeners, depending on their individual personalities and dispositions; and even the more restrained listeners might still enjoy some

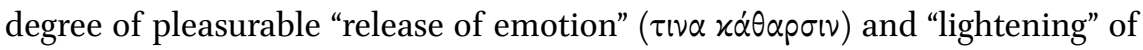
their mood ( $\varkappa \cup \cup \varphi i \zeta \varepsilon \sigma \theta \alpha \mathrm{l})$.

As he continues (1342a16-28), Aristotle explains that musicians competing in the theater and at festivals should be allowed to use the more affective modes and melodies, particularly for the "relaxing entertainment" ( $\dot{\alpha} \alpha \dot{\pi} \pi \alpha v-$ $\sigma(v)$ of the lower-class, less sophisticated elements in the audience ("craftsmen, laborers, and such like"); yet he acknowledges that there is also a more

39 The next sentence presents a problem of reading and interpretation. In the MSS, we have "Similarly, 'kathartic' melodies ( $\tau \dot{\alpha} \mu \dot{\varepsilon} \lambda \eta \tau \dot{\alpha} \varkappa \alpha \theta \alpha \rho \tau \varkappa \alpha \dot{\alpha})$ provide harmless pleasure to peo-

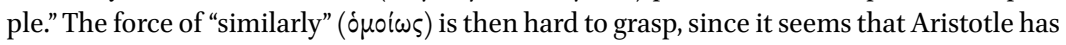
already been discussing "kathartic" melodies in the preceding sentence. So several editors and translators (including Ross in his 1957 OCT) follow Sauppe in reading $\pi p \alpha x \tau i x \alpha$ for $x \alpha \theta \alpha p \tau i x \alpha$ (picking up on 1342a4, just above). The main thrust of Aristotle's argument is not affected by our choice of reading. 


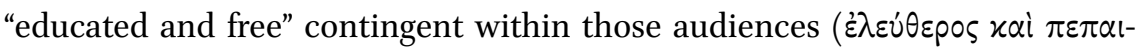
$\delta \varepsilon \cup \mu \varepsilon^{\prime} v \circ \varsigma$ ), even while he implies that these discriminating listeners will be less affected than the vulgar lower classes by the "extremely strained and colorful" melodies ( $\sigma \dot{v} v \tau o v \alpha$ xai $\pi \alpha \rho \alpha \kappa \varepsilon \chi \rho \omega \sigma \mu \varepsilon \dot{v} \alpha)$. He sums up: "What belongs naturally

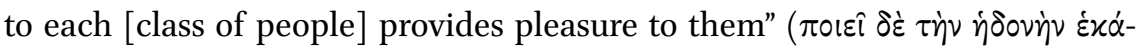

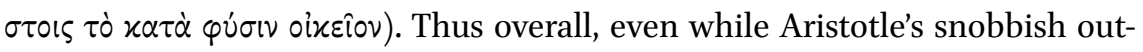
look leads him to insist that the more emotionally affective types of music appeal more to the lower classes, it is quite clear that (unlike Plato) he does not consider the more extreme forms of emotional arousal and relief to be appropriate only for defective human beings. One does not have to be a baby, or demented and pathologically fearful (as e.g. at Leg. 79oc-791b), to enjoyand benefit from-listening to (and perhaps even participating in? ${ }^{40}$ these exciting, "enthusiastic" music-forms and songs, even though they surely would not be so suitable for the leisured discussion-sessions and critical appreciation $(\delta 1 \alpha \gamma \omega \gamma \eta$ ') of Aristotle's citizens, nor obviously for the teaching of children in school. ${ }^{41}$ And from the Poetics we learn that Aristotle thinks that attending the theater to watch and listen to tragedies being performed can be both highly pleasurable and quite "philosophical," even while he is fully aware that all the music played there is accompanied by the auloi and much of it is in Phrygian harmonia.

It is remarkable-but should not be surprising to us-that Aristotle is so comfortable in acknowledging that enthusiastic/orgiastic/sacred/Bacchic/ pathos-inducing music is going to be widely available and highly valued in his (and any) polis. He seems to take this for granted as a normal social fact. This does not mean that he thinks most of his population will need or will want to engage in full-scale Korybantic therapy (a process which we will discuss below). Rather, he stipulates that, even while most people will not actually fall into ecstatic trance states in listening to Phrygian music played on the auloi

40 At 1342a3-4 Aristotle stipulates that in the context of education, students should only be exposed to "ethical" harmoniai, but that adults should be allowed to listen to all kinds. (He has also previously proposed that boys should only learn to play instruments well enough to be able as adults to appreciate and critique music played by others.) So the actual performing of e.g. Phrygian tunes on the auloi should be left to others ( $(\dot{\tau} \varepsilon \dot{\rho} \rho \nu \chi \varepsilon i p-$

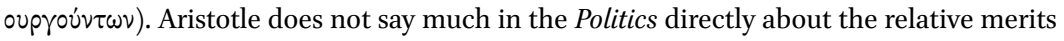
of listening/watching vs. performing, for those who seek only "relaxation, fun" — but his remark about the relaxing effects of dance (1339a17-21) includes the comment "some people think ...," as if he himself is dubious. Aristotle never engages in direct discussion of the social value of dance and choral performance within a community, as Plato does (see esp. Peponi 2013b; Prauscello 2014).

Aulos-music at gentlemen's symposia was of course absolutely normal, almost mandatory. 
(i.e. such states are just for actual "patients" seeking a katharsis-type cure), most people nonetheless do get affected by such music to some (more limited) degree, and they derive harmless pleasure from listening to it. As Aristotle phrases it (1340a8-14), music of the affective genre, such as Olympus' aulosmelodies, "by common agreement makes [people's] souls 'enthusiastic', and enthousiasmos is an affective reaction of the ethos involving the soul" ( $\delta \delta$ ' $\varepsilon v \theta 0 v-$

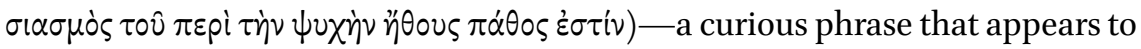
mean by pathos a temporary stimulation and alteration of physiological and mental state. Such "arousal/alteration" occurs for a relatively short period of time, and the whole process of arousal and subsequent calm does not bring about permanent change in the character, disposition $(\hat{\eta} \theta 0 \varsigma)$ of the listener; hence such music does not fall into the "ethical," i.e. character-building, category. ${ }^{42}$ The auditory stimulation of "enthusiastic" music provides for almost everyone harmless excitement and pleasure-in Aristotle's terms, "fun" ( $\pi \alpha \mathrm{l}-$ $\delta(\alpha)$ ) and "release, relaxation" ( $\left.\alpha^{\prime \prime} \varepsilon \sigma \iota \varsigma\right) .{ }^{43}$ In the field of musical performance, then, we can say that "enthusiastic" music comprises a large but distinct genre with a specific function; and within this genre, actual Korybantic-type performances (which obviously entail additional activities beyond simply listening to "musical" sounds) constitute a particular, relatively small, sub-set. We may observe too that Aristotle seems to recognize that the large and capacious genre of "enthusiastic" music overlaps to some degree with the genre of competitive "theater music" and thus also with the ("literary") genres of dithyramb, tragedy, and comedy, i.e., genres which include high-art, virtuoso specimens of enthusiastic, aulos-accompanied song-types.

42 Aristotle seems to hold the same opinion about going to the theater: watching (and listening to) a good tragedy arouses quite strong emotions $(\pi \dot{\alpha} \theta \eta)$ — especially pity and fear-in the audience members; but the resultant "katharsis of such emotions" does not alter their character permanently in the way that Plato's Socrates asserts in the Republic. For further discussion of this (controversial) issue, see esp. Halliwell 1998; Sifakis 20o1; also Bernays $1857 / 2015$.

43 For a full and fascinating exploration of Aristotle's katharsis, see esp. the long discussion of Bernays 1857/2015 (which has often been consulted by subsequent scholars only in abbreviated form, and consequently misrepresented and misinterpreted: cf. Porter 2015). Bernays argues convincingly that the katharsis provided by music or drama according to Aristotle entails a process of stimulus-and-release/relief of emotions/affect that is relatively brief, short-term, and self-contained; the process is in itself exciting, pleasurable, experience-enhancing, and repeatable. Thus his position is not so far from that of Halliwell 2011: $236-265$ as the latter suggests. 


\section{Musical Genres and Emotional Arousal (Possession/Trance/Ecstasy): Comparative Evidence}

The Greeks were not unusual in their appetite for musically induced possession or trance, nor in their recognition that such kinds of musical experience fall into a distinct category. Rituals designed to elicit or facilitate altered states of consciousness through music are widespread and well-documented, from many different regions of the world. The most wide-ranging investigation of this phenomenon remains that of Gilbert Rouget (1980/1985), though several important studies since then have shed further light on particular contexts and on some of the neurological, physiological and psychological processes that are involved. ${ }^{44}$ This is not the place to try to discuss in detail all the various aspects of this rich and complex topic; but a brief summary of the current state of anthropological and neuroscientific knowledge concerning strong emotional arousal in response to music should help us see the ancient Greek phenomena in appropriate context(s).

Listening to and enjoying music in general for humans-and apparently the same is true of several animal species as well-depends on fairly elaborate neurological processes of expectation-arousal and satisfaction. A series of acoustic stimuli provokes listeners, on the basis of their previous experience of the conventions of the musical "language" of their particular society, to recognize formal patterns as they develop and are elaborated, modified, and perhaps challenged before finally resolving themselves into a (somewhat intelligible and reassuring) cadence and "sense of an ending." 45 The neurological processes involved in listening to music have much in common with listening to and interpreting human speech, though of course in the case of music, factors of pitch, regular rhythm (meter, "beat"), and tonal timbre tend to be more finely and precisely calibrated. ${ }^{46}$ Anticipation, tension, build-up of emotion/affect,

44 Rouget's book was first published (in French) in 1980; the second edition (significantly revised, and in English translation) appeared in 1985. Rouget discusses ancient Greek (1985: 187-226) and Arab culture (255-314), as well as many different kinds of possession, trance, shamanism, exorcism, initiation, etc. that involve music in various parts of the world. His book is surprisingly seldom mentioned in Anglophone classicists' discussions of ancient Greek music. Among more recent publications I have found useful especially the following: Becker 2001, 2008; Juslin and Sloboda 2001; Nettl 2005: 244-258; Bicknell 2009. See too Keil and Feld 1994; Sacks 2008.

45 Meyer 1956.

46 Meyer 1956; Kivy 1989, 1990; Davies 2003; Levitin 2006; Patel 2008. For non-human (animal) responses to music, see e.g. Wallin et al. 2000; Marler and Slabbekoorn 2004; Kroodsma 2005 . 
and release - along with inherently pleasurable regularities of rhythm, variations in vocal or instrumental textures, and possible memories or associations imported from previous social contexts-all combine to make the process of responding to music both intensely personal/individual and yet also to a large degree (in most human societies) communal, predictable, and programmable. And among the various different kinds of music that any particular society may have developed, there are usually certain types that lend themselves especially well to a program of lengthy build-up of mood and sustained expectation, and the response to these musical types more often than not involves not only "passive" listening but also active bodily movements of some kind (dancing, swaying, hand-clapping, foot-stomping, etc.) on the part of the listeners/participants. ${ }^{47}$ In these respects such kinds of performance may be said to conform to the parameters of a "genre," with performers and participants/listeners alike all operating within a recognized and adaptable set of expectations and "rules"rules that include a significant—-though variable—component of embodied audience response. ${ }^{48}$

Musically-induced states of altered consciousness that we refer to as "possession," or "trance," or "ecstasy,"49 are an empirically observable and welldocumented phenomenon. Those who enter such a state display an accelerated heart-rate, lighter and more uneven pulse, shallower breathing, increased body temperature, and significantly altered patterns of brain activity. In most cases, those "possessed" respond corporeally to the music by dancing and/or vocalizing or gesturing..$^{50}$ Musical "possession" in many cultures is induced through regular and carefully controlled mechanisms, whether as a religious ceremony, a form of therapy, or simply entertainment, and it is usually a collective event. But at the same time it is a subjective process, in that any individual who enters into the process will only become "possessed" if s/he wants to. Unlike, for example, magic spells or drugs, one cannot through purely musical and performative means make someone succumb to these effects if that person is not already so disposed.

47 Rouget 1985: 114-119, 201-206, and passim; Becker 2001.

48 Compare the chapters by Olsen, Estrin, and Weiss in this volume.

49 The terms "trance," "ecstasy," "possession" are unfortunately not defined or employed consistently by most anthropologists or musicologists. Objectively, there is more than one kind of emotional arousal that can arise from music and that might be classified as "ecstatic." Rouget 1985 makes a strong distinction between the "ecstasy" of a listener who enters an altered state of extreme quietness and contemplation and the state of "trance" in which bodily movement and active participation in the musicking are usual. 
Almost all trance-inducing performances deploy some acoustic effects, and most of them use designated instruments and/or a singing style of some distinctive kind: that is to say, there is usually a recognizable "soundscape" and character to trance music within a given society. But this sound can be very different from one culture to another. Thus, even though some scholars have claimed that particular musical instruments, or particular rhythmic patterns, are the universal key to producing altered mental and physiological states, in fact the processes are quite variable and culturally specific. ${ }^{51}$ Usually a professional group of experts leads and supervises the performance; these may or may not be the musicians themselves. Sometimes the musicians enter a trance state along with the listeners/dancers; but sometimes the musical performers remain in a calmer and more distanced mood while the dancers and/or other listeners become "possessed."

Even while trance music can come in many forms (as can the physical manifestations of a "possession" state), usually such music is designed so as to maintain a steady rhythm and/or repetitive melodic pattern, thus prolonging the in-between stages of "listening," i.e., deferring the "sense of an ending" and resultant release of tension, so that listeners are drawn into participating continuously in these regular and perhaps gradually intensifying patterns. In some trance performance traditions, singing (often more or less improvised) is an important component and the words may be central to the experience; in others, the emotional impact is provided almost entirely by instrumental music instead, even while sometimes the participants may add improvised or repetitive vocalizing of their own. The duration of a single trance performance is usually rather extended (as compared with other types of song or instrumental recitation); and this may allow each of the members of the congregation/group to arrive at her/his state of heightened consciousness or trance at different moments in the ceremony. Thus while the whole performance will usually begin at a relatively low level of volume and intensity, the build-up will be sustained long enough for the whole group to get engaged, though not necessarily

$51 \quad$ So for example the once widely-believed claim that drums are key to trance-inducing has been shown to be unfounded; likewise the claim that $5 / 8$ or $11 / 8$ rhythms invariably have such effects on all listeners: see Rouget 1985: 73-94, 169-176; Becker 20o1; Bicknell 2009: 77-79. In all ancient Greek contexts, as Rouget notes, the almost mandatory acoustic ingredient is the pipes (auloi), while percussion instruments are prominent in some ceremonies but not in all "enthusiastic" music-making: see further below. In general, the musical idiom through which trance is effected may allow for many variations, depending on the specific focus of a performance and its participants: see e.g. Rouget 1985: 100-102 (tarantism) and passim. 
all at the same moment or with the same degree of intensity. ${ }^{52}$ But again one must bear in mind that the overall character of the music and of the associated dance and movements, or even the overall purpose of such "possession," may be different from one culture to another. ${ }^{53}$

The use of music for healing purposes in general is a broader phenomenon than "trance music" and "possession" ritual, since there are countless different processes through which people may find music effective in a process of bodily or mental therapy, in contexts of, for example, trauma, memory loss, depression, and various kinds of social dysfunction. Music therapy of various kinds was known and practiced quite extensively by the Greeks (as by most other societies); but in this chapter I am considering only the types of musical therapy that employed trance/possession. ${ }^{54}$

Finally, a note on demographics and language. Trance/possession performances are most commonly found among socially disadvantaged or marginalized communities, rather than as a component of "high" culture or mainstream religion. ${ }^{55}$ Many of the best known and most socially impactful modern contexts of possession/trance performance (leaving aside Western disco/techno/ house/trance forms of dance music $)^{56}$ are most widely practiced by women and/or the socially disadvantaged: e.g., North African zar (Sudan/Egypt, Morocco, Mali, etc.); Haitian voudun; American Pentecostal ceremonies. In some

$5^{2}$ Becker 2001 discusses several examples, including (at 146) Sufi qawwal performances in Pakistan and North India and (at 149-150) Pentecostal performances in the USA.

53 Becker 2001: 141-143 offers a helpful analysis of the different processes and effects of a silent, physically motionless Western listener responding to and appreciating a piece of classical music - even a highly "emotional" piece—vs. the engagement of a Sufi celebrant during a mevlevi (Dervish) or qawwal performance, or (146-149) the interaction between musicians, masked dancer, and audience in a Balinese bebuten gamelan performance designed to arouse the participants' anger to the point where they can collectively defeat and exorcize the evil witch Rangda who is threatening the whole community. In this latter case the emotional arousal is not inherently pleasant, but the overall social outcome of the performance is one that brings calm and satisfaction to all.

54 On music therapies in the modern world, see Becker 2001; Bunt and Pavlicevic 2001; Sacks 2008; Yinger 2017. For ancient Greece, see Jeanmaire 1949; Barker 1984: index s.v. "healing."

55 See Rouget 1985 passim. Exceptions obviously exist, such as the Ottoman version of the Sufi dancing of the Mevlevi orders (Dervishes). Several Persian and Arabic writings in the Sufi tradition acknowledge the possibilities of attaining closer access to God through such musical processes (e.g. Abu Hamid Al-Ghazali's Alchemy of Happiness [Kimiya-yi Sa'ādat]). By contrast, modern Salafi and Wahabi doctrine presents a very different view of music's value.

$5^{6}$ I leave these aside not because they are irrelevant, but because the sociological, demographic, religious, and aesthetic elements seem to be too complex and shifting to be easily summarized. 
cases, the ceremonies are conducted in a language that is not that of the dominant culture and that may not even be well understood by many of the celebrants: thus the "foreignness" of the divinities who are imagined to control the event is underlined, and the special expertise of the ministrants is duly authorized as well. ${ }^{57}$ The sense of "escape" from normality and of liberation from the pressures of the dominant culture outside the performance event may also temporarily be enhanced. These features seem clearly to have been true of classical Greece, at least for certain forms of ecstatic music-making in Attica, a point to which we will return towards the end of this chapter.

\section{Korybantic and Other "Enthusiastic" Musical Performances in Classical Greece}

Bearing in mind the comparative material that we have surveyed, as well as Aristotle's statements about "enthusiastic" types of music from the previous section, it is time now for us to focus directly on ancient Greek Korybantic-type rituals, to see whether these should qualify as a distinct "genre" of performance, and if so, whether they should count as "lyric." In this section I consider a number of ritualized, mood-altering, and in some cases trance-inducing ancient musical performances, which seem to fall roughly into three separate but overlapping categories.

In the first category we may place initiation ceremonies that were specifically said to be conducted by or for the Korybantes or similar entities (Kouretes, Kabeiroi, Dactyls), with ministrants (i.e., designated officials or priests) presiding over a sequence of organized events, some of them musical. A second category-perhaps not always distinct from the first-comprises therapeutic rituals performed in the name of the Korybantes that employed music and other sounds and sights to induce extreme affective states, including terror, disorientation, and even hallucinations, in one or more participants, resulting in behaviors that might lead observers to conclude that these participants were temporarily "out of their minds." A third, broader category consists of a range of exciting, musically-enhanced performances of the kind that were generally described (for example, by Plato and by Aristotle, as we have seen)

57 Rouget 1985. In the ancient Greek context, cf. Parker 2005 on the Athenians' growing penchant in the fifth and fourth centuries BCE for Bendis-festivals and other Thracianor Phrygian-tinged performances; also Wilson 2009 on the exotic (especially Thracian) associations of Thamyris and Orpheus as imagined "originators" of Greek musicality, and G. Martin 2009 . 
as "orgiastic," "enthusiastic," "sacred," or "Bacchic," and that are usually associated with divinities such as Cybele or Rhea (the Great Mother), Sabazius, or Dionysus - whether or not the Korybantes or similar daimonic entities are explicitly involved as components of the ceremony. ${ }^{58}$

These categories are not hard and fast. The second should perhaps be considered only a sub-division or modified — or intensified — version of the first, while the distinction between the first (specifically "Korybantic/Kouretic" etc.) and the third ("Bacchic/Sabazian/Cybelean/orgiastic/enthusiastic," etc.) is by no means always clear or absolute. As we shall see, there was a strong tendency in antiquity to blur some of these distinctions and indulge in what Bourdieu calls the "fuzzy logic" by which analogous or similar-looking behaviors end up being lumped together in the social imagination as being all the "same"in this case, musical and performative elements that all cluster to the right end of our grid (Table 1) - even when in some cases they may involve some significantly different features and functions. As we shall see, Greek authors, including especially Plato and (less so) Aristotle, often slide rather casually and fuzzily from one set of terms to another in describing "Bacchic" and "Korybantic" performances, without making a clear distinction. For the purposes of our discussion of lyric genres it may not matter much in the end whether a particular (type of) performance was or was not specifically "Korybantic," or should be categorized as more indeterminately "Bacchic." But a brief survey of the different types will help us come to recognize both the broader contours and some of the recurrent and distinctive features of the rather capacious musical genre that Aristotle referred to as "enthusiastic."

The various different groups of minor divinities (daimones) that were named Korybantes (or Kyrbantes), Kouretes, Kabeiroi, or Idaean Daktyloi, must originally have been quite separate cultural entities, celebrated in different places by different people, each with their particular melodies, dances, etc., during the Archaic period and into the early Classical period. ${ }^{59}$ But these distinctions became conflated and confused as time went on, even while separate local cults for one or other group persisted ${ }^{60}$ and aetiological myths continued to circu-

$5^{8}$ The purely figurative use of $x o p v \beta \alpha \nu \tau i \alpha$ ' $\omega$, to denote extreme excitement of any kind, will crop up here and there (esp. in Plato), but does not need a separate category.

59 For full discussion and references, see esp. Poerner 1913; Burkert 1985: 8o, 173, 28o-285, 297; Parker 1996, 2005: 120-121, 373-374; Bowden 2010; Bremmer 2014. Ustinova 19921998 attempts to treat Korybantic cult as a more or less self-contained and distinct phenomenon, and focuses largely on Athens.

6o So for example Plato's Socrates remarks (Ion 536c2-4): "The Korybantic devotees have a quick ear for only one tune, the tune of that god by whom they are possessed, whoever

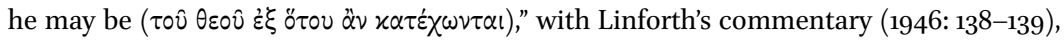


late linking each to different origins and locations. By the late fifth century BCE there was also a habit of referring generically to any kind of psychotherapeutic treatments for mental or spiritual distress that involved music or other loud sounds along with ritualistic/ecstatic movement and dance as "Korybantic." Hence (more broadly) anyone who was behaving in a very eccentric manner might be said figuratively to be "Korybanting" even when no real connection to daimonic (Korybantic or other) musical ritual was present.

Let us begin by quickly surveying the particular names and aetiologies for these various daimones, since these on the face of it do provide some evidence about their musical and performance characteristics. The Korybantes or Kyrbantes seem to have originated in Anatolia, as associates of Cybele the Great Mother. Sometimes described as wearing triple-crested helmets, they are imagined as dancing and making percussive music among her retinue. ${ }^{61}$ Late (perhaps Orphic) sources describe them singing and dancing noisily around the enthroned baby Dionysus, protecting him from the Titans. ${ }^{62}$ The Kouretes were imagined as youthful armed warriors (hence perhaps kouroi), and were primarily associated with Crete and the birth of Zeus, and thus also with Rhea, i.e., another version of the Great Mother. Their noisy clashing of shields and vocalizing are supposed to have drowned out the cries of baby Zeus and/or to have frightened away Kronos when he was seeking to capture and destroy his son. ${ }^{63}$ The Kabeiroi are most fully attested in Lemnos and Samothrace, apparently as metal-working daimones - the number varies, from two, three, or four to a whole band - while another branch of their cult (a sixth-century вСE Kabeirion) was established also at Thebes. ${ }^{64}$ Jan Bremmer and others have

observing that there must have been many different versions of Korybantic performance, each one favoring "one particular tune."

61 Immisch 1897; Poerner 1913; Schwenn 1922; Linforth 1946; Burkert 1985: 80, 173, 280-285; Parker 1996, 2005; Bremmer 2014: 48-53. "Kyrbantes" was said to be the Phrygian form of the name, but the etymology is unknown (see Bremmer 2014: 48-49). We may note that early Iron Age illustrations of Phrygian (or "neo-Hittite") music-makers depict extensive use of cymbals, frame-drums, and double-pipe, and in some cases several of the performers appear to be wearing distinctive head-gear (though not helmets). In the classical period and later, at Erythrae (an Ionian Greek city in western Anatolia) an annual dual priesthood for the Korybantes is recorded, to be held by a man and woman: see Herrmann 2002.

62 Burkert 1984: 297; Edmonds 2006.

63 Harrison 1912; Poerner 1913; Jeanmaire 1939; Burkert 1985: 280. One of the earliest attestations of the Kouretes occurs at Eur. Cretans fr. 472.9-19 TrGF; see also the Palaikastro Hymn (discussed below, n. 73).

64 Poerner 1913; Hemberg 1950; Burkert 1985: 281-285; Daumas 1998; Blakely 2006; Constantakopoulou 2015: 281-284. 
suggested that the Samothracian mystery cults were modeled to some extent on the Eleusinian Mysteries; ${ }^{65}$ but the Kabeiroi themselves, as metal-workers, seem to have no Eleusinian equivalent, and the Theban Kabeirion does not much resemble anything from Eleusis. ${ }^{66}$ As for the Idaean Dactyls-likewise metal-working daimones - these were of course connected to Mount Ida (on Crete) and to the Great Mother, but they otherwise seem to have little by way of a distinctive identity. 67

Some have seen all or most of these cults as being connected with male adolescent rites of passage, but the evidence for this is very thin. Walter Burkert, Sandra Blakely, and others have suggested instead that several of these cults

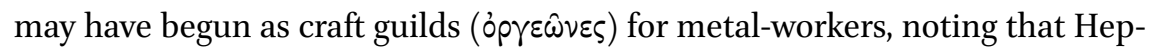
haestus continues to be prominent in the cult of the Kabeiroi. But then the connections with Cybele and Rhea are not easy to explain. Probably there were several different origins and specific ritual functions for these various cults, and only later did homogenizing aetiologies (and names) come to be assigned. ${ }^{68}$ But whatever the precise origins of each particular cult, we can observe that the performative elements (choice of instruments, use of nonverbal vocalizing, unchoreographed dance and movement) and divine sources (Asian, Cretan, Thracian) for all of them belong squarely on the right end of our grid (Table 8.1).

As many scholars, ancient and modern, have pointed out, a blurring of distinctions between these various groups, their names, origins, and characteristics, had begun already by the fifth century $\mathrm{BCE}^{, 69}$ and such blurring was doubtless especially pervasive in a multicultural environment such as classical Athens. Thus in Euripides' Bacchae, the chorus of Asian Bacchantes sing of Crete and the joyous music of the Phrygian mother:

65 Bremmer 2014: 22-36, with further references.

66 The iconography (vase paintings and figurines) from the Theban Kabeirion presents many scenes of drinking and carousing, several of them involving pygmy-like and other grotesque (fat, ithyphallic) human or daimonic figures. Many of the scenes show pipeplayers as well; see Daumas 1998. The singular name Káßıpos is sometimes found, along with $\pi \alpha \hat{i}$ ("child" or "son"), but there is scant evidence for any sort of coming-of-age ritual.

67 Burkert 1985: 173. On the Dactyls as metal-working daimones, see Blakely 2006.

68 For adolescent rites of passages (kouroi Kouretes, etc.), see esp. Harrison 1912; Jeanmaire 1939. On metal-working, see Burkert 1985:281-285; Blakely 20o6. For emphasis on the wide range of different functions served by "mystery cults" in general, see Burkert 1987; Bowden 2010.

69 So already in Pherecydes ( $F G r H 3$ fr. $48=$ fr. 48 Fowler) the Kabeiroi and Korybantes are combined; see further Hemberg 1950: 304; Bremmer 2014. 
O holy places of Crete, the caves of the dancing Kouretes, there where Zeus was born, where helmed in triple tier the Korybantes invented this leather drum; and with their intense god-filled dance ( $\beta \alpha x x \varepsilon i \alpha)$ they mixed the drum-beat with the sweet cry of the Phrygian pipes. Then, from them to Rhea's hands the holy drum was handed down, to give the beat for Bacchantes' dances, and, taking up from the Mother, the raving/inspired ( $\mu$ alvó $\mu \varepsilon v o l)$ Satyrs now accompany the festivals in which every other year Dionysus delights! EUR. Bacch. 120-134, tr. W. ARROWSMITH, adapted

This is quite a delicious jumble: Kouretes and Korybantes and Satyrs all together, or in sequence; Crete and Phrygia, Rhea and Cybele (the Mother) and the Bacchantes, along with Dionysus himself-all one great musical party. This chorus has been performing all over Asia, we are told (Bacch. 13-22, 55-59, etc.), and is now beginning the process of importing their new musical styles into mainland Greece. Presumably the theater audience at this point is hearing and seeing a performance that was designed by Euripides and his musical collaborators to recall to some extent "Korybantic" song, whether or not a full panoply of percussion was employed in the production in addition to the standard theatrical double-pipes (auloi). But the description leaves open the possibility that the musical elements may have been modified during the course of the transmission of these instruments from the Korybantes to the Bacchantes, Satyrs, and Dionysus. Nowhere in this description is there any suggestion of initiation, $\theta$ póv $\omega \sigma \iota \varsigma$, or terror and confusion being aroused among the participants (as, for example, Plato tends to describe Korybantic rituals), nor of healing the mentally ill-instead the celebrations seem not only exuberant but entirely cheerful.

In another choral song from tragedy—but a completely different imagined context - a famously obscure, but highly evocative, passage in Euripides' Helen (1337-1352) narrates the invention (or so it appears) of a new kind of music, long ago, to cheer up the distraught Deo/Demeter when she had lost her daughter Persephone and was bitterly blighting the crops all over the world. ${ }^{70}$ Here there

70 Elements of Rhea, Cybele, and Demeter seem to be combined in this passage, even while the mention in 1342-1343 of "Deo" and "the Girl" ( $\pi \dot{\alpha} \rho \theta \varepsilon v \circ \varsigma)$ makes Demeter obviously the prime referent. See further Allan 2008 ad loc. 
is no mention of Korybantes, nor of any male participants at all in the musicmaking (indeed, the context requires that "Deo" be comforted only by female companions). But the insistence on the "chthonian voice of bronze" (either a rhombos or cymbals, or possibly a gong) and "skin-strung drums" (tumpana), as well as "deep-sounding auloi," suggests a similar soundscape to that described in the Bacchae passage. This scene takes place on Mount Ida (Hel. 1324)—but which one? Is this the Great Mother in Anatolia? Or is Demeter-Rhea imagined here as being in Crete? In either case, she is surrounded by exciting, semiarticulate female vocalizing (1344 $\left.\dot{\alpha} \lambda \alpha \lambda \hat{\alpha}, 135^{2} \dot{\alpha} \lambda \alpha \lambda \alpha \gamma \mu \hat{\omega}\right)$ and double-pipes in combination, and the result is a transformation of her mood and of her relationship to her surroundings. It even appears that the Mother herself begins to play the pipes. ${ }^{71}$ Whether this scene is entirely Euripides' invention, or is based on actual Greek musical practices and/or cult reenactments known to his Athenian audience, it is only intelligible if that audience is already familiar with the idea that such combinations of voices and instruments, producing music that apparently relies much more heavily on rhythms, melodies, and timbres than on words, could conventionally be expected to have strong and positive affective impact, in particular on someone in a deeply depressed state.

In a later period (first century вСE), Strabo observes explicitly (Geography 10.3.7) that those various Kouretes, Korybantes, Kabeiroi, Daktyloi, and even

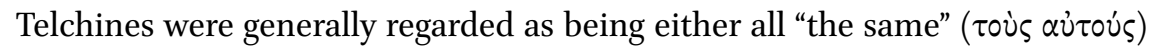

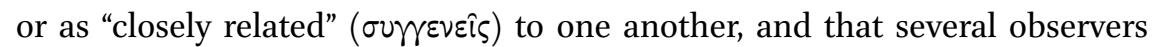
"differentiate only certain small matters in which they differ in respect to one another; roughly speaking and in general ( $\tau \dot{\tau} \pi \omega)$, they represent them, one and all, as a kind of inspired people ( $\dot{\varepsilon} v \theta_{0} v \sigma \alpha \sigma \tau i x \circ v$ s) and as subject to Bacchic

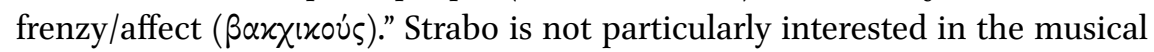
aspects of these cults/performances, but he confirms that the typical instruments employed are cymbals, tumpana, and metal shields, along with auloi; the

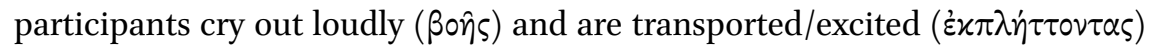
also by the movement/costume $(\sigma \times \eta \dot{\eta} \mu \tau \iota)^{72}$ of the attendants. In what follows (10.4), Strabo expands his account, noting that such rites were "common" to

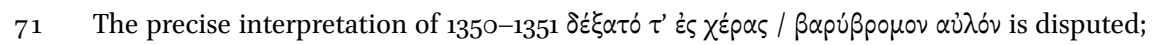
some critics prefer to take this as Deo "welcoming" the sound of the instrument rather than actually playing it. See further on this passage Weiss in this volume.

$72 \Sigma \chi \eta^{\prime} \mu \alpha \tau \iota$ in Strabo's account here is ambiguous, as to whether it means the "costume" of the

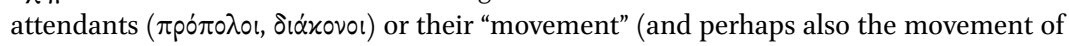
the celebrants themselves?): $\sigma \chi \hat{\eta} \mu \alpha$ can often mean "dance-step, choreography" or "physical arrangement, gesture." In either case, a strong visual and corporeal component of the ceremony seems to be entailed. 
Hellenes and to barbaroi; some were public, others were mystery-cults; some

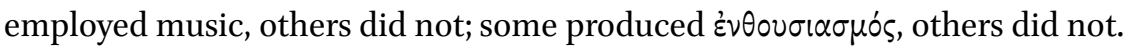

Several Hellenistic and later writers provide quite detailed aetiologies for one or other of these differently-named spirits and their musical activities, but these tell us little about the actual musical and performance characteristics of the rituals as practiced in the classical period. ${ }^{73}$ From that period, we do find Euripides and Aristophanes (both in the 420s) including references to "Korybantic" possession as a form of mental distraction as if this is something already quite familiar to their Athenian audience. But unfortunately these references are brief and not easily interpreted. In Euripides' Hippolytus (141-147) the Chorus speculate about the reasons for Phaedra's distress as she tosses and turns wildly on her bed, and propose the Korybantes as one of several possible causes. ${ }^{74}$ The references in Aristophanes' Wasps (5-10, 118-123) are even more difficult to sort out. At the beginning of the play two bored and sleepy slaves, who have been ordered, with threats from their master, to stay awake all night on guard duty, are comparing notes as to whether their sleepiness is due to a Korybantic state (8-9) or to Sabazius (10). Sabazius was a Thracian and/or Anatolian divinity similar in attributes and characteristics to Dionysus, and his rituals were especially popular with the laboring classes in Athens, including slaves, and with women. ${ }^{75}$ The notion that one might enter a state of pleasant drowsiness and thus "escape anxiety" ( $\dot{\alpha} \pi \mu \varepsilon \rho \mu \eta p i \sigma \alpha l, 5)$ with the help of Korybantic ritual or devotion to Sabazius suits the situation well, though in this case the drowsiness does not seem to have been triggered by any musical or communal performance.

A little later in the play, Xanthias describes how Bdelycleon tried to "cure, purge" ( $(\dot{\alpha} \theta \alpha i \rho$ ', 118) his father of his obsession with jury duty by various therapeutic means:

73 For example: Callim. Hymn 1 (to Zeus) 46-57 (on Kyrbantes, Kouretes, the nurse Amaltheia, and baby Zeus); Aratus, Phaen. 30-35 (Dictaean Kouretes); Nonnus, Dion. 46.1318 (Rhea, Korybantes, and baby/kouros Zeus). At least one account (apparently from a lyric poet, of unknown date) suggests that these entities were not in fact daimones, but were the very first human beings ( $P M G /$ Campbell 985 a and 985 b; paraphrased by Hippol. Haer. 5.17). Another fascinating lyric poem of the Hellenistic era, the so-called Palaikastro Hymn to the Kouretes $\left(I_{3}\right.$.2) refers to Rhea, the birth of Zeus and the "shield-bearing [nurses]," but otherwise contains no "Korybantic" or ecstatic elements (pace Harrison 1912; see Fontenrose 1966 and esp. Alonge 2008).

74 It seems that the implication here is that her condition is involuntary; Pan and Hecate are also mentioned as possible sources of her mental distraction.

75 Parker 1996: 161-162, 191-194, 2005: 325. See below for discussion of the involvement of Aeschines and his mother Glaucothea in running a Sabazius cult in Athens. 
Then he tried a Korybantic treatment ( $(\dot{x} \circ \rho \cup \beta \alpha \dot{v} v \tau \zeta)$ ); but his father rushed into the Common Court, tumpanon and all, and resumed his jury activity! AR. Vesp. $119-120$

In this (ludicrous and exaggerated) scenario, old Philocleon was apparently quite willing to join a Korybantic group, but the strength of the possession that he underwent there was not sufficient to overpower his maniacal desire to keep judging cases and he simply channeled the ritual energy into continued activity in the lawcourts. Although the two slaves' enjoyment of Sabazian and/or Korybantic release in the earlier scene seems to entail a very different process from the "rituals" ( $\tau \varepsilon \lambda \varepsilon \tau \alpha \hat{\imath} \zeta, 121)$ that the old man has experienced, in both cases the affected person has clearly entered an altered state and hence for some hours responded to his situation very differently from those who were not thus "possessed," though in the one case the result was frenetic activity, in the other sleepiness - presumably successive phases of the Korybantic/Sabazian ritual process.

Of all classical Greek authors the one who most frequently and prominently mentions "Korybantic" things is Plato, as Ivan Linforth observed in his careful and much-cited 1946 article. Plato's dialogues include seven passages where the term crops up, whether in a shorter or longer discussion: Crito $54 \mathrm{~d}$; Euthydemus $277 \mathrm{~d}-\mathrm{e}$; Phaedrus 228b-d; Ion $533 \mathrm{~d}-536 \mathrm{~d}$ (twice); Symposium 215c-e; Laws $790 c-791 b$. Unfortunately for our purposes, the discussions are mostly facetious, so that it is difficult to determine how much is metaphorical, how much literal in these Korybantic references, and how seriously to take what is said by Socrates or by the Athenian Visitor in the Laws, or by their various interlocutors. Linforth is certainly right, however, in observing that Plato (like Euripides and Aristophanes) takes for granted that his Athenian and wider Greek reading public is pretty familiar with Korybantic activity, and his descriptions are vivid and often amusing.

There is no need to go through all these passages in detail here. ${ }^{76}$ For the most part, Plato refers to "Korybantic" behavior as a humorous foil for more creditable, rational activities of the kind recommended by Socrates or the Athenian Visitor. That is to say, people who indulge in Korybantism, whether literally or metaphorically, are over-excitable, and are engaging with the world in a quaint and intellectually defective way, one that is characteristic of children or

76 The most thorough, nuanced, and judicious—and best known—discussion remains that of Linforth 1946, though he has small interest in the musical aspects of any of the passages and perhaps also understates the degree of Plato's purposeful unreliability. See also Dodds 1951: 77-79; Rouget 1985: 187-22o; Ustinova 1992-1998; Parker 1996, 2005; Edmonds 2006. 
over-impressionable and neurotic adults. Thus in Phaedrus (228b-d), the terms "Korybantic" and "Bacchic" appear to be used interchangeably (and metaphorically) to describe reactions of extreme delight at listening to a speech composed by Lysias. Similarly, in Ion (533e-534a) Socrates describes the sources and effects of artistic creativity with an amusing comparison to both Korybantic and Dionysian ecstasy, as he claims that lyric poets, like participants in Korybantic rites, are "possessed" ( $\propto \tau \tau \varepsilon \chi o ́ \mu \varepsilon v o l)$ and "not in their right minds"

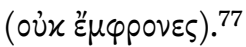

A passage from Plato's Euthydemus $(277 \mathrm{~d}-\mathrm{e})$ provides a rather detailedand again humorous - description of a Korybantic initiation process. Socrates suggests that, just as in the preliminary stages of Korybantic ritual a person is surrounded by swirling motion and confusing sounds, as s/he is carried around and "enthroned" in preparation for his (or her) culminating initiation, so has his young Athenian gentleman-friend Clinias been subjected by the two unscrupulous sophists, Euthydemus and Dionysodorus, to a purposely confusing hubbub of clever arguments as a warm-up for their big, revelatory performance of sophistry to follow. ${ }^{78}$ The actual process whereby the enthroned person is gradually rendered more and more excited in anticipation, before attaining the final state of initiated bliss, is not explained here. Some other accounts describe the initiand's state as one of terror (recalling the rituals of the Eleusinian Mysteries), but most trance rituals, especially if conducted with music and dancing, involve a more positive anticipatory mood, as well as movement (rather than inert sitting) on the part of the main participants. If the "enthronement" ( $\theta$ póvw$\sigma(\varsigma)$ is meant to recall that of baby Zeus or Dionysus, it is not clear whether the "baby/initiand" is supposed to be more terrified or comforted by the musicafter all, it should, in mythical terms, be the (absent) father Kronos or the murderous Titans, not the musical Korybantes, that are to be feared.

An even more extended-and whimsical - account of Korybantic procedure is provided by a well-known passage in the Laws (79oc-791b) which refers to the healing power of such ritual. Here the Athenian Visitor explains how the expert ministrants and musician(s) of the Korybantic and/or Bacchic ritu-

77 For discussion of Plato's notions of creative "madness" and "possession" in Ion and Phaedrus see e.g. Dodds 1951: 64-101; Rouget 1985: 188-201; Halliwell 2011; cf. too [Longinus] Subl.39.2.

78 Socrates includes a phrase "[as you know], if in fact you've actually been initiated [your-

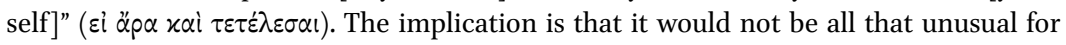
a well-brought-up young gentleman such as Clinias to have experienced this ceremony

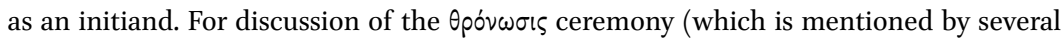
other authors as well, some of them probably influenced by Plato), see further Ustinova 1992-1998; Edmonds 2006. 
als, ${ }^{79}$ just like mothers and nurses of new-born babies, calm the agitated celebrants by means of incessant "shaking" and "movement": this, he suggests, is also the explanation for adult pleasure and satisfaction in choral dancing to music. Plato puns here on the words for "nursing" ( $\tau \theta \theta \dot{\eta} \nu \eta \sigma v)$ and "moving" ( xiv $^{\prime} \sigma v$ ), suggesting that dance-movements and the power of the double-pipes to "induce trance-states" ( $\dot{\alpha} \tau \varepsilon \chi \nu \omega \hat{\omega}$ o oiov $\varkappa \alpha \tau \alpha \nu \lambda \circ \hat{\sigma} \sigma \mathrm{l}, 790 \mathrm{e})^{80}$ provide effective treatment for people who suffer from acute mental-spiritual instability (i.e., are like babies), with the implication that normal, healthy adults would find no occasion for such treatment. Clearly we should not swallow too much of Plato's tongue-in-cheek analogy here. ${ }^{81}$ Nonetheless, its observations about the effectiveness of trance music and dance (especially the reference to auloi and $\varkappa \alpha \tau \alpha \nu \varepsilon^{\prime}(\omega)$ in drastically altering the physiological and mental state of participants, bringing them to a pitch of excitement and exhilaration, and finally leaving them exhausted and pleasantly calm, squares well with other references to this kind of performance, including Aristotle's account from the Politics.

The Symposium presents another vivid and famous simile, as Alcibiades compares the effect of listening to Socrates' voice to being possessed by Korybantic music (215e). Strikingly, as Linforth observes, this explicitly "Korybantic" reference follows more or less continuously upon an extended reference (215d) to the aulos-compositions of Marsyas and Olympus, which generally

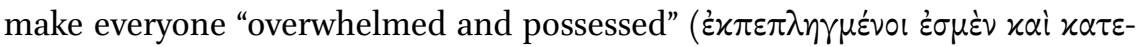
$\chi^{\prime} \mu \varepsilon \theta \alpha$ ). Marsyas the satyr and his (human) student Olympus have nothing really to do with Korybants (and Alcibiades makes no mention of percus-

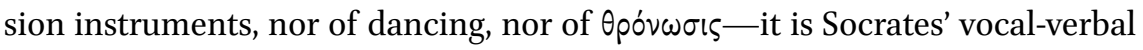
impact that Plato wishes to highlight). Thus once again we seem to be dealing with a spectrum of musical-ritual responses, causing varying degrees of affective arousal that range from the almost universal experience of listening to pipe-music in Phrygian mode ${ }^{82}$ to the more extreme and particular experi-

79 The Visitor specifies "the women who officiate in the healing rituals of the Korybants" ( $\alpha i$

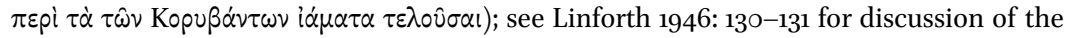
interpretation and translation of this phrase. Elsewhere in the same passage the Visitor describes the participants in these rituals as being "in the grip of Bacchic frenzy" ( $\tau \hat{\omega} \nu$

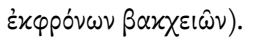

8o The term $\varkappa \alpha \tau \alpha u \lambda \varepsilon \dot{\varepsilon} \omega$ means specifically to "play the auloi to get someone to enter a trance state," i.e., "to entrance them with the pipes"; cf. Eur. HF 867-879, 892-899; Pl. Rep. 411a. See further Rouget 1985: 201-202.

81 The Visitor concludes by underscoring his frivolity with a mock-solemn claim: “... this

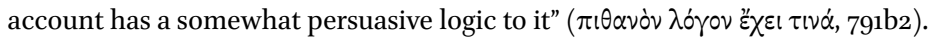

82 The semi-mythical Phrygian piper Olympus was widely regarded as the source of the basic 
ences specific to Korybantic ritual. ${ }^{83}$ Within everyday fifth- and fourth-century BCE Athenian discourse, the terms "Korybantic" and "Bacchic"—or in some cases "Sabazian" - or even "aulos-musically-affective" and "enthusiastic" can all apparently be employed almost interchangeably.

A particularly vivid sidelight on Sabazius-cult in Athens, and on the larger phenomenon of "enthusiastic" performances in general, is provided by the remarks of Demosthenes in the course of his notorious character-assassination of his rival Aeschines, in his speech On the Crown. Here he harps on the abject poverty of Aeschines' whole family and the demeaning occupations that they took up in order to earn a living. Aeschines' father had been a school teacher, and his mother, assisted by Aeschines himself as a young man, was leader of a Sabazius cult:

You assisted your mother in her rituals ( $\tau \varepsilon \lambda \circ \sigma^{\circ} \eta$ ) and at night you would read out loud the [sacred] books and helped prepare all the paraphernalia - the fawn-skins, the mixing bowl ... washing and purifying the participants ..., and you were especially proud of the fact that nobody ever

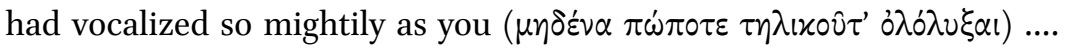

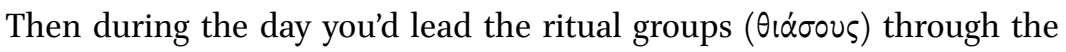
streets ... squeezing the snakes and raising them above your head, crying

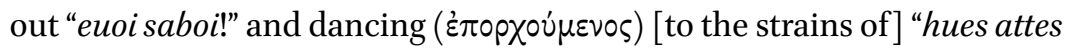

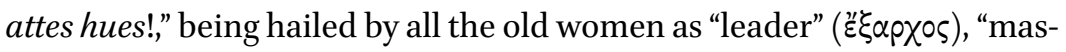
ter of ceremonies" ( $\left.\pi \rho \circ \eta \gamma \varepsilon \mu \omega^{\prime} \nu\right)$...

DEM. $18.259-26$ o

The performances clearly had much in common with Dionysian celebrations (mixing bowl, fawn-skins, snakes, etc.), while the ululations and foreign-sounding ritual incantations seem to provide a rather "Thracian" flavor, even while Aeschines' family were themselves completely Athenian. ${ }^{84}$ Demosthenes tells

Greek aulos-repertoire, much as Terpander was credited with having founded the kithararepertoire. The tunes attributed to Olympus were not all in Phrygian harmonia: some were e.g. in Dorian (Barker 2012). See further Barker 1984, 2012; West 1992: 105, 163-164, 181.

83 The disturbing impact of the pipes is also mentioned by Socrates in a Korybantic context near the end of Crito (54d), though the reference is rather obscure; cf. (contra Harte 1999) Griffith 2017 n. 13.

84 G. Martin 2009: 106-117 argues that the foreign-sounding ingredients in this description are largely an artificial invention, either by the Athenians in general (who generally liked to mix all kinds of "exotic" features into their Dionysus-celebrations) or by Demosthenes for rhetorical effect, and that there is little or nothing specific to Sabazius in this description, except possibly the snakes. He suggests that Demosthenes' account is a "hotchpotch 
us nothing about the musical aspects of these celebrations (e.g., what instruments were used to accompany the chanting and dancing), and he is more concerned to highlight the incongruity of an adult Athenian man participating in such activities - and even taking a leading role in them - than to discuss their effect on the (mainly female?) celebrants who paid (apparently with cakes rather than cash) to participate in the thiasos.

Altogether, the evidence concerning specific Korybantic rituals is thus quite various and some of it is confusingly inconsistent, even while the "fuzzy logic" of cultural analogy can be observed in the various more or less casual references of our classical sources, jumbling together the multifarious phenomena in rather consistent and predictable ways. We see that both male and female musicians and conductors/ministers/leaders of the ceremonies are attested, but we do not know quite how they were supposed to relate to the mythical daimones whose cult they were promoting. ${ }^{85}$ The original Korybantes (and Kouretes, Kabeiroi, etc.) themselves are male, while the nurturing goat Amaltheia is female and the whole idea of "nurses" for baby Zeus or Dionysus implies some female presence (such as the Meliae nymphs; cf. Plato's remarks in the Laws passage). Similarly many of the more plainly Dionysian groups of celebrants in myth include both satyrs and nymphs (or maenads), whether or not the god himself, or a male priest, personally presides over the drinking and dancing. ${ }^{86}$

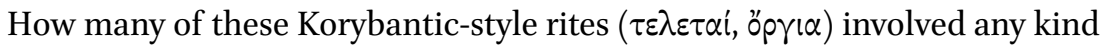
of "initiation" and/or "enthronement"? How similar or different was an initiation-type Korybantic ritual from a healing-type ritual? (Might they be two stages of the same ceremony?) In the case of healing ceremonies, we can assume that if an individual was selected to be thus healed s/he must usually have been recognized as being in a particularly troubled mental/spiritual state,

of various rites," with intentional exaggeration and absurd details included for humorous effect. On Greek incantations ( $\dot{\varepsilon} \pi \omega \delta \alpha i)$ in general, see Furley 1993.

85 In Hellenistic and later times, we find inscriptions recording e.g. that citizens $\mathrm{X}$ and $\mathrm{Y}$ served $a s$ the Kabeiroi in a given year, i.e., that this was an annual office; see Herrmann 2002. But this is presumably not the original pattern: human priests and ministers cannot normally become the actual gods or daimones being invoked, even if they may mimetically represent them in some respects.

86 See e.g. Parker 2005: 306-312, Scullion n.d. for discussion as to whether, and if so in what capacity, men could and did participate along with female celebrants in Dionysiac rituals at Athens. In the case of the Eleusinian Mysteries, the chief ministers of the cult were male (from the aristocratic Eumolpid clan), but the initiates were both male and female (including slaves), all apparently celebrating together. For discussion of the musical components of the Eleusinian (and other) Mysteries, see esp. Hardie 2004. 
whereas if a largish group met up for a celebration not all of the participants would be in the same state of spiritual need, though it is possible that different individuals would find themselves engaged and excited to different degrees during the course of a performance (as often happens in such trance contexts). In the case of initiation ceremonies, we might also conjecture that the initiand (e.g., someone like Socrates' young friend Clinias) may not always have been selected because of their state of mental disturbance, i.e., was not always seeking the same kind or degree of therapeutic treatment and cure. Many may have attended such ceremonies in a spirit more of "play" than of initiation, and those who enjoyed Dionysian celebrations were certainly not confined to women and those at the margins of society.

Further questions present themselves: were these ceremonies usually public or private? Were they conducted indoors or outdoors, at night or by day? Were they usually domestic and focused primarily on one person's cure or initiation? Or were they group sessions, in which many might join in as the mood took them, like other kinds of Dionysian thiasoi? ${ }^{87}$ Did the participants recognize a significant difference in function and performance character between specifically "Korybantic" rituals (and their equivalents: Kabeiroi, Kouretes, Dactyls), and other orgiastic and "enthusiastic" celebrations involving such individual gods as Sabazius and Bendis, Cybele, and even Adonis? As we have seen, casual parlance could apparently refer to almost any such cult performances as "Bacchic." 88

Even if we cannot answer all these questions in the present state of the evidence, enough common features and procedures are identifiable amidst this multifarious range of names and cults for us to regard them collectively as a single broad "type" of religious and musical event-a genre, analogous, for example, to our contemporary genre of "Electronic" popular music, with its many sub-categories and multiple additional sub-divisions. ${ }^{89}$ Even while the particular divinities might vary, and only a rather small proportion of these

87 Rouget 1985: 103 asserts "Every, or almost every possession cult has two aspects, that of its private rituals, reserved for the initiates or those being initiated, and that of its public rites, in which both adepts and followers of the cult take part and which more or less always take the form of a performance in which possession dances constitute the main element." This seems to square well with our evidence for ancient Korybantic and generally Dionysian rituals.

88 I will leave out of consideration here so-called "Orphic" documents, since whatever musical elements may or may not have been involved, these do not seem to have had much in common with Korybantic-style ritual. See further Edmonds 2008, 2013.

89 Within the "Electronic" category, "House," for example, includes “Acid," "Rave," "Tribal," etc. 
Dionysian/Cybelean-type performances might be classified as strictly "Korybantic," the common elements of the genre can be fairly definitely specified: loud music (almost always involving auloi, and often also animal-skin-drums and metal percussion instruments), vigorous movement (whether dance or other gestures), and an unusual degree of emotional arousal and altered men-

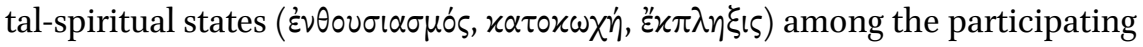
group, culminating in a "release" and a pleasant, prolonged mood of exhausted calm or sleep. Vocalizing of one kind or another was often included, but not always: in any case the music that was being performed did not depend on words for much - if any — of its effect. Women comprised a high proportion of the participants and performers, and elements that were regarded by elites as "non-Greek" and/or "banausic" (low-class, vulgar) were prominent. With regard to "Greek song culture" as a whole, this range of performances thus consistently occupies a far-right position on our grid, even while it appears already by the fifth century вСЕ, and probably earlier, to be quite deeply embedded within the social fabric-i.e., not a new foreign import nor a marginal activity confined to social misfits.

\section{Conclusions: Enthusiastic Performance as a Lyric Genre}

Greek song-culture offered multiple venues and occasions for musical performances, often of a non- or subliterary kind and supported by aulos-playing, that could be enjoyed by people from all social classes, in small or larger groups. These events - which in many cases might be regarded as "religious" celebrations (hence Aristotle's use of the term "sacred" [iєpós] and "Bacchic" interchangeably with "enthusiastic") — provided entertaining and stimulating auditory experiences that in their intensity often went beyond the casual "fun, play" of more neutral listening, and thus beyond the milder forms of relaxation outlined by Aristotle under the category of $\pi \alpha \iota \delta$ ' $\alpha$ and $\alpha \dot{v} \varepsilon \sigma ı \zeta$. These occasions provided escape from the drudgery of work and the stresses of everyday reality, and in some cases also served as an opportunity for some kind of healing of spiritual

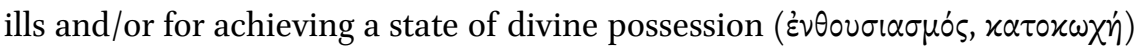
in the company of a group of like-minded companions. The words of the songs that were performed at these events were, for the most part, relatively unimportant: the emphasis was more on the melodies, rhythms, vocal and instrumental timbres, i.e., the overall auditory stimulation and the strong - and pleasantemotional affect (pathos) that these could induce-and sometimes also on the opportunities for dancing. Spontaneous, improvised participation in the music-making by the celebrants themselves might often constitute a feature 
of some of these performances, which consequently might or might not be counted as "choral," depending on one's definition. ${ }^{90}$

Some of the occasions at which Aristotle's most "enthusiastic" and emotionally affective kinds of music were performed involved ritual celebrations explicitly linked to the Korybants, Kouretes, Kabeiroi, or other local daimones of this kind. Others were less specific, more vaguely/generically "Bacchic," including several in honor of Cybele, Sabazius, etc. For most of these "enthusiastic" and "sacred" performances, the polis (or deme) as such usually had little to do with the organization and design of the events: they were organized instead by

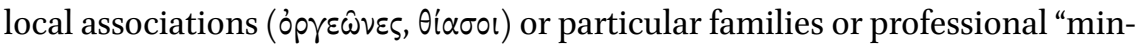

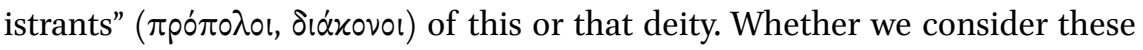
performances to be private or public, they seem to have been available to virtually every member of any Greek community, male and female, including metics and slaves, and to have been ubiquitous. I suggest that we should expand our idea of Greek "lyric genres" so as to include these somewhat déclassé/subliterary and even nonverbal types of performance, and that we should recognize, as Aristotle seems to have done, that it was specifically their emotional/affective impact on listeners (and on performers) that justified their being considered a distinctive genre of their own.

Modern scholars tend to treat these various "Bacchic" and orgiastic ceremonies as aspects of "Greek religion," and to discuss them in terms of the belief-systems and ethnic/gender/social identities that they might have represented and fostered. Their subliterary (and in some cases completely nonverbal) nature has meant that they have not generally been included in ancient or modern discussions of Greek song-culture (let alone lyric poetry), or only as a marginal postscript to it. Yet the evidence suggests that these "Bacchic"including more specifically Korybantic-type-occasions constituted a significant fraction of the "songs" and performances that would have been heard and seen from month to month in any given community. We should acknowledge the distinctive artistic, performative, and affective dimensions of such celebrations, and regard them as constituting a vibrant genre within Greek song culture, running in parallel to the more mainstream and socially elevated cultural forms that we find most prominently discussed and defined in our surviving literary sources.

$90 \quad$ See e.g. Budelmann and Power 2015, for discussion of various forms of women's "choral performance" in Athens that have mostly passed below the historians' and cultural critics' radar, including semi-formal "Bacchic" events. 
Most of our ancient sources that discuss the history of Greek poetry or music focus on high-end productions and performances, just as American and European music historians and critics tended until quite recently to focus only on the Western European art music tradition ("Classical" music). Discussions of the Greek symposium have tended likewise to focus more on the verbal exchanges and poetic sophistication of the male symposiasts than on the musical contributions of the professional and/or slave musicians, who in most cases were presumably rather more accomplished on their instruments than the actual guests. ${ }^{91}$ The fact that "Bacchic" musical events in general, outside the theater and other competitive festival contexts, were so readily available to such a wide range of people, in terms of gender, ethnicity, and social class, together with the high degree of emotional (and often corporeal) engagement that many of these performances entailed, meant that our elite sources consistently relegate them to the margins of their discussions and/or write as if they catered only to the vulgar or the demented. But on closer inspection it looks as if all kinds of people enjoyed such performances, in one context or another, and they deserve a more prominent position among our standard lists of Greek "lyric genres."

The Athenian theater-and in due course, theaters all over the Greek world-made the most of this type of music and performance too, incorporating it readily into dithyrambs and (especially) dramas, in which highly emotional rituals and songs could be mimetically reproduced in more or less authentic styles. The aulos-fueled music of the Athenian theater ${ }^{92}$ depended on a well-trained cluster of experts who between them could provide virtuoso pipe-playing, elaborate choreography, and an extensive range of melodies for the delight of thousands of audience-members. How closely these theater performances resembled the less culturally exalted and less heavily (finan-

91 Many scholars write as if the $\alpha \dot{\lambda} \lambda \eta \tau p i \delta \varepsilon \varsigma$ who played at these symposia were little more than cheap prostitutes, whose musical skills were secondary or negligible; but see e.g. Goldman 2015.

92 The dithyrambs and dramas performed in the Theater of Dionysus seem mostly to have employed Phrygian and Lydian harmoniai, though other modes could be used as well. The same is probably true of the music performed at symposia. But it is obvious that not all Phrygian melodies on the auloi were thought to have an "enthusiastic" effect, and we do not hear of people becoming possessed and going into a quasi-Korybantic trance at the theater or at a symposium. So it was only certain particular types of pipe-melody that were especially suited for producing this kind of pathos (affect, effect), and-crucially, as we noted above-it was only those who were positively seeking the trance effect who would find themselves so transported by music. 
cially) subsidized genre of actual (non-mimetic) orgiastic/enthusiastic ritual performance, we cannot tell. In those real-life cases, the degree of vocal and choreographic training, coordination, and uniformity shared by the performers would usually, one may conjecture, have been much smaller than in the case of dithyramb or tragedy - though the participation of women must have added a significantly fuller and richer dimension to the soundscape than the all-male performers in the theater could ever have attained. As we noted above, some Korybantic/orgiastic performances may have dispensed with verbal song completely, confining the vocalizations to shouts, ululations, and other more or less inarticulate cries, and inviting the celebrants (unlike the theater audiences) to enter or exit the music-making as the mood struck them. In the case of the two Euripidean examples that I discussed above, i.e., the mixed-status celebrants of Cybele/Rhea/Dionysus in Bacchae and the female friends who come to console Deo/Cybele/Rhea with their music in Helen, it is the nonverbal textures of the music that seem most prominent and salient, and it is these (above all, the auloi) that are cited as being most characteristic of this genre of mood-altering performance.

The fact that many of these kinds of performances were conducted by non-citizens-often by non-Greeks (or by Greeks pretending to be nonGreeks) ${ }^{93}$ —adds another dimension to this genre, and will have added to its déclassé status. And, to return to my grid (Table 8.1), this fact must have significantly affected the ways in which language was and was not employed in the different types of Korybantic and Bacchic musical performance. Clearly the melody, the timbre of the auloi and percussion, and the rhythm of the music and corporeality of the dance, were largely what induced in a listener the exhilaration and ascension to a state of altered consciousness and perhaps trance/ healing, while the actual words uttered by the ministrants or by the participants themselves do not seem generally to have been very important, or even always to have been coherent Greek. Foreigners and slaves - those with limited capabilities as users of the Greek language-would thus be just as capable of accessing these trance states as anyone else. The Korybantes (whatever/whoever they are supposed originally to have been) were not Greek. The Kouretes and Dactyls were Cretan (i.e., only borderline-Greek). The Kabeiroi seem not even to have been entirely anthropoid. The exotic character of these daimones was essential to the imagined origin and effect of their music, whether or not

93 This should be the topic for a separate paper; but meanwhile see Parker 1996: 170-175 (young men dressing up as Thracians to celebrate the goddess Bendis) and Power 2010: 47-48, 257 (a fashion for "Thracian chic" among kitharodes in Athens). 
Cybele or Rhea or Dionysus or Sabazius was directly invoked as well. The music over which all of these daimonic entities presided was appreciated particularly because it was different from that of the Olympian hierarchy, and the $\dot{\varepsilon} v \theta 0 v \sigma-$ $\alpha \sigma \mu o ́ s$ that it could instil was a precious cultural asset. Even Greek gentlemen might engage in a little "enthusiasm" from time to time. They recognized that this might be good for them, and as Aristotle noted, this musical genre constituted a vital component of their "song culture." 